NBSIR 81-2411

\title{
An Examination of the State of the Art in Inland Waterways System Lock Research
}

U.S. DEPARTMENT OF COMMERCE National Bureau of Standards National Engineering Laboratory Center for Applied Mathematics Washington, DC 20234

February 1982

Final Report

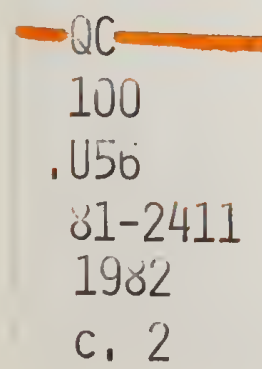

Prepared for:

Navigation Division

Institute for Water Resources

Kingman Building

Ft. Belvoir, VA 22060 



\section{AN EXAMINATION OF THE STATE OF THE ART IN INLAND WATERWAYS \\ SYSTEM LOCK RESEARCH}

Martin H. Pearl

U.S. DEPARTMENT OF COMMERCE

National Bureau of Standards

National Engineering Laboratory

Center for Applied Mathematics

Washington, DC 20234

February 1982

Final Report

Prepared for:

Navigation Division

Institute for Water Resources

Kingman Building

Ft. Belvoir, VA 22060

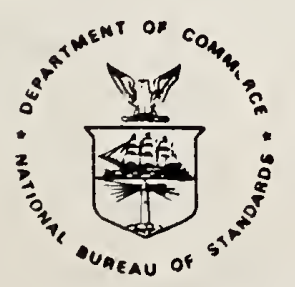

U.S. DEPARTMENT OF COMMERCE, Malcolm Baldrige, Secretary NATIONAL BUREAU OF STANDARDS, Ernest Arr bler, Director 

Table of Contents

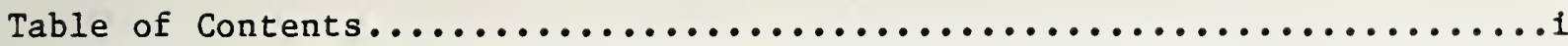

List of Tables.........................................

Abstract..............................................111

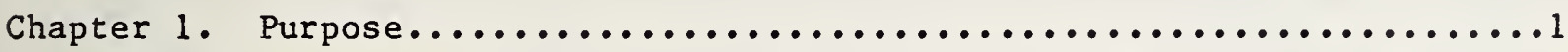

Chapter 2. Navigable Waterways of the United States................

Chapter 3. Maintaining the Inland Waterways System...............7

Chapter 4 . The Operation at a Lock.............................

Chapter 5. Barge Traffic on the Inland Waterways System.............16

Chapter 6. Attacking the Problem.............................19

Chapter 7 . Simulations (The Early Years)......................23

Chapter 8 . Simulations (Part 2)...........................

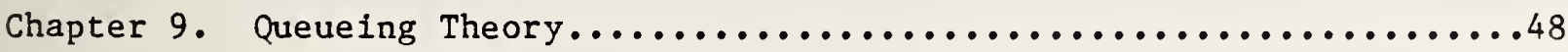

Chapter 10. Queueing Theory Applied to a Single Chamber Lock..........53

Chapter 11. Queueing Theory Applied to Multiple Chamber Locks........666

Chapter 12. Queueing Theory in the Foreign Literature..............75

Chapter 13. Input and Performance Data......................

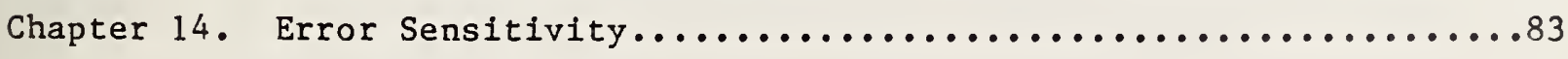

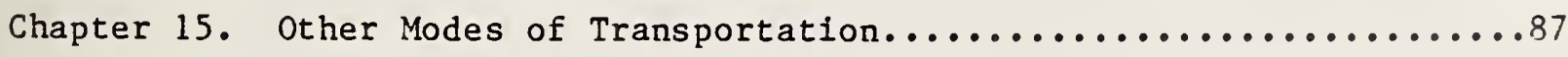

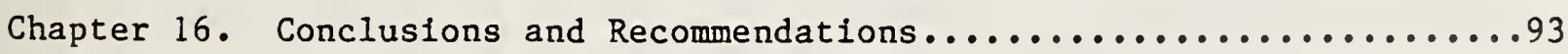

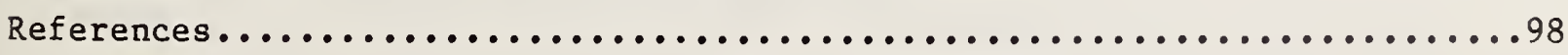




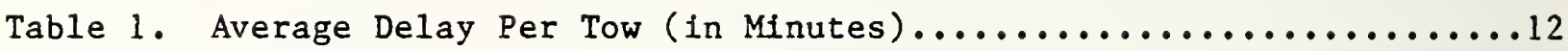

Table 2. Typical Locking Times (in Minutes).....................14

Table 3. Towboats and Barges of the United States (1971-1975).........17

Table 4. Towboats and Barges on the Inland Waterways System (1975)......18

Table 5. Predicted and Observed Total Waiting Time in Queue............54

Table 6. Comparison of Carroll's Simulation results with Wilson's M/G/l

Result and Results Using Lave and De Salvo's $M / M / 1$ model ......60

Table 7. Comparison of Observed and Calculated Averate Waiting Times for

Each Chamber at Lock and Dam No. $26 \ldots \ldots \ldots \ldots \ldots \ldots \ldots \ldots \ldots \ldots$

Table 8. Average Delays per Tow with Alternative Queueing Models

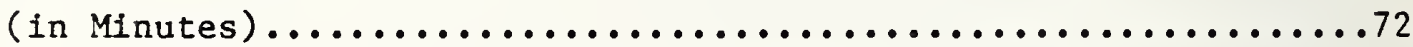

Table 9. Actual Data Compared with $M / M / 1$ and $M / G / 1 \ldots \ldots \ldots \ldots \ldots . . \ldots . . .74$ 


\section{Abstract}

The dams encountered on the locking rivers of the inland waterways system are needed in order to maintain depths (usually nine feet) sufficient for tow traffic. At the same time, the locks which pass waterborne traffic through these dams act as bottlenecks and interfere with the free flow of traffic. As the level of traffic seeking to pass through a lock approaches the practical capacity of the lock, congestion and delays develop. The simplest and cheapest way to decrease the long delays commonly found at the busier locks in the United States is to modify the operation of the lock in order to increase its efficiency. However, the problem of determining the maximum capacity of a lock and the operating procedures which achieve this efficiency is a difficult one. Two complementary mathematical tools have been used in attempts to solve this problem. They are

- computer simulations of traffic flow,

- the mathematical theory of queues.

The earliest computer simulation of the operation of passing a tow (consisting of a towboat and a flotilla of barges) through a lock was performed by J. L. Carroll in 1965 [9]. Since then, many (groups of) researchers working independently in various parts of the world have produced numerous computer simulations of barge traffic on locking waterways. In 1971, a large-scale, multi-purpose simulation package was developed at the Pennsylvania Transportation and Traffic Safety Center (PTTSC), Pennsylvania State University, University Park, Pa. by a team working under Carroll's direction. The portion of this package devoted to traffic on a locking river consisted of three parts: 
- TOWGEN - the generation of a time stream of tows and an origindestination matrix,

- WATSIM - the movement of the tows of the system from origin to destination,

- LOKSIM - the passage of each tow through each lock between its origin and its destination.

Since 1971, the PTTSC package has been modified, reprogrammed, expanded and generally refined (primarily under sponsership of the U.S. the Army Corps of Engineers) and is today the accepted simulation package for modeling river traffic in the United States. It appears to be far superior for general purpose use than any competitor produced elsewhere in the world.

The second tool which has been used extensively for studying the capacity of a lock is mathematical queueing theory. The first attempt to apply queueing theory to the operation of a lock was made by Lave and DeSalve in 1968 [31, 56]. Shortly after these papers appeared, the question arose (and was debated by Hayward [44], Wilson [82], and others) as to whether or not the basic assumptions needed to make the queueing scenario mathematically tractable (e.g. the assumption that the service times required by different tows are independent) reflect the actual performance of a waterway. Subsequently, several authors (e.g. Rochberg [72], Glassey and Ross [40], etc.) attempted to follow up the work of Lave and DeSalvo in order to make the results predicted by the model agree more closely with data obtained both from actual waterway operations and from computer simulations. In general, these attempts have not been satisfactory and the task of constructing an adequate queueing theory model remains open. 
Each mode of transportation has generated its own reservoir of research. Queueing theory has been used in studying aircraft landings and take-offs at an airport, automobile traffic at an intersection, automobile traffic on a single-lane bridge or roadway, etc. One major purpose of this report was to examine this model 1iterature and to analyze the research developed therein with an eye on applying portions of it to the lock and dam scenario. This examination demonstrated that the state-of-the-art in lock and dam oriented research is at least on a level with that applied to other model transport problems and the possibility of finding helpful new ideas in this literature is not sanguine. 



\section{Purpose}

Since the end of World War II, all modes of transportation, both in the United States and in the rest of the world, have been experiencing ever-increasing demands on their facilities. During this period, both passenger traffic and freight tonnage has grown constantly. At the present time, the level of demand on many of the transportation networks has approached the limits of available capacity, resulting in serious delays, congestion and, ultimately, the diversion of traffic. Faced with this ever-growing demand, the agencies charged with the responsibility for maintaining a smooth, orderly flow of traffic, have responded in two complementary ways:

- improving the efficiency of the existing facilities in order to increase their capacities (usually by changing the rules under which the facilities operate),

- expanding the facilities in order to increase the capacity of the system (usually by additional construction or new equipment).

Increasing the efficiency of an existing system presents a simpler, easier and certainly cheaper way to accommodate additional traffic than is afforded by construction.

Many of the problems arising in each of the various modes of transportation are common to all of them and it has frequently been found that the same basic problem has been studied in several different contexts. However, the research efforts that have been engendered by these problems are invariably directed at (as well as supported by, tested within, etc.) a single mode of transportation. It is reasonable to expect that studies dealing with capacity problems which have been developed under the auspices of one mode of transportation can contribute to the solution of problems facing other modes 
of transportation. It is the two-fold purpose of this paper to examine the state of the art in passing barge traffic along a locking waterway, and, to evaluate research dealing with other modes of transportation with the aim of applying this research to the lock and dam scenario. 
2. Navigable Waterways of the United States

There are 25,543 miles of navigable waterways in the United States (including those which have been improved by the Federal Government and other agencies and those which have not been improved) which are capable of supporting conmercial traffic $1 /$ of this, 2,371 miles consist of the protected waters of the Gulf of Mexico and The Atlantic Intracoastal Waterways, 490 miles of the Great Lakes and the remaining 22,682 miles are composed of the various river systems (the Inland Waterways System) of the continental United States and Alaska. The Inland Waterways System comprises the Mississippi River, its tributaries and connecting waterways ( 8,954 miles), the Atlantic Coast Waterways including the New York State Barge Canal and the Hudson River System (5,570 miles), the Gulf Coast Waterways, consisting of a network of rivers which empty into the Gulf of Mexico (4,292 miles), and the Pacific Coast Waterways $(3,575$ miles $)$.

A waterway is called "locking" if the movement of traffic on it is made possible by the use of a system of locks and dams. Waterways which have no need for locks and dams in order to provide sufficient draft to move traffic are called "open". Where necessary, channel depth in open waterways in usually maintained by dredging. The lower Mississippi River (south of St. Louls), the Hudson and Missouri Rivers and the eastern portion of the Gulf Intracoastal waterway are examples of open waterways. The upper Mississippi River (north of St. Loufs), the Ohio and Illinols Rivers and the western portion of the Gulf Intracoastal Waterway are examples of locking waterways. This paper deals with locking waterways exclusively.

\footnotetext{
$1 /$ The Inland Waterways System serves both pleasure craft and commercial vessels. The commercial traffic is by far the greater of the two. In most analyses of waterway traffic, pleasure craft are ignored.
} 
Since the second world war, there has been a very rapid growth in the use of the Inland Waterways System. From 1961 to 1976, there was a 57\% increase in the tonnage carried on the Inland Waterways System and a $117 \%$ increase in tonmiles $2 /$. During the same period, the increases in the Coastal Waterways traffic have been $10 \%$ and $2 \%$ respectively. The growth in the use of the Inland Waterways System has far exceeded all forecasts and has placed a considerable burden on the existing facilities. In 1975, over two trillion tonmiles of intercity freight were shipped by all modes of transportation in the United States. Of this, $12 \%$ traveled by rivers and canals, and an additional 5\% used the Great Lakes. The remaining $83 \%$ of freight transported between cities traveled by rail ( $37 \%$ ), highway ( $21 \%$ ) and pipeline ( $25 \%)$.

Waterborne commercial traffic in the United States consists mainly of barge transport of industrial commodities (coal, petroleum products, iron ore, etc.), agricultural commodities (grains, soybeans, lumber, etc.) and lesser amounts of manufactured products (paper, machinery, chemicals, etc.). In 1975, there were 946 million tons of waterborne commodities shipped domestically and 748 million tons of waterborne commodities in foreign shipments. About $65 \%$ of domestic marine traffic travels by barge and the largest portion of this $(77 \%)$ is on the Inland Waterways System.

The Western Rivers System is the portion of the Navigable Waterways System consisting of the Mississippi River, its tributaries and connecting waterways, the Gulf Intracoastal Waterway and the navigable river system emptying into the Gulf of Mexico. The largest part of the inland freight which is transported in shallow-draft vessels uses the Western Rivers System. Of the

\footnotetext{
2 The large difference between these rates of increase will be discussed later.
} 
roughly 25,000 miles of navigable channels in the United States which are capable of carrying commercial traffic, about 14,000 miles are contained in the Western Rivers System and about 8,700 miles of these have a limiting depth 3 / of at least nine feet. It is in the Western River System that the most rapid growth of waterborne traffic has taken place in recent years. The rapid rise in ton-miles of freight ( $117 \%$ ) compared to the rise in tonnage ( $57 \%$ ) between 1961 and 1976 reflects the increased use of the Western Rivers System, where barge journeys are usually significantly longer than elsewhere in the Inland Waterways System. Although this rapid growth in traffic has placed a severe strain on all navigational facilities, it is at the locks and dams which are needed to maintain navigable waters in the Western Rivers System that the greatest impact has taken place. In times of heavy traffic (which is virtually all of the time in some places), locks and dams are not able to pass vessels as quickly as they arrive and bottlenecks are created which slow river traffic substantially. Vessels which cannot be served at a lock as soon as they appear for service must wait (often for several hours) their turn in a queue. The response to this problem of delay at a lock is the major focus of this report.

When a direct water route between two points is available, the cost of transporting freight from one point to the other on the Inland Waterways System is generally less than when using any other mode of transportation. In spite of the long queues at locks which have become commonplace in recent years, many shippers still feel that the low cost of waterborne freight movement overrides other considerations. In addition, as the price of petroleum fuel (for trucks

\footnotetext{
3 /The limiting depth of a channel is the minimum depth that is maintained along the entire length of the channel at all times.
} 
and railroads as well as for river tows) goes up, the cost advantage of shipping via the Inland Waterways System can be expected to increase 4 . Thus, the rapid growth in demand for services that the Inland Waterways System has been experiencing since the second world war is likely to continue. Clearly, unless some substantial changes are made either in the physical system itself or in the way that the current system is used, the delays presently taking place on the Inland Waterways System (especially on the Western Rivers System) will become progessively longer. Eventually, the long delays will motivate some shippers to seek faster, though more expensive, modes of transportation. This added cost will be passed on, resulting in higher prices for the consumer (for goods destined for the domestic market). For goods shipped in international commerce, the added cost will tend to make American exports less attractive.

\footnotetext{
4 / The competitive price advantage of waterborne traffic may change if the proposals for tolls at locks should be implemented.
} 


\section{Maintaining the Inland Waterways System}

In 1824 , Congress appropriated $\$ 75,000$ to improve navigation on the Ohio and Mississippi Rivers. The task of making these improvements fell to the Army Corps of Engineers. This marked the beginning of the Corps' long involvement with the national waterways. Since then, the maintenance and improvement of the existing inland waterways and the planning, design and construction of new waterways has remained their responsibility. For fiscal 1977, Congress appropriated 2.5 billion dollars to the Corps for civil works. Of this amount, almost 660 million dollars were earmarked for projects dealing with navigation.

A substantial portion of the Corps' current work deals with modernizing and standardizing inland navigation -widening, straightening and deepening channels, building higher dams and larger locks and striving for uniform dimensions of barges, tows and locks. In recent years, the Corps has devoted a great deal of effort to an attempt to alleviate the bottlenecks which now exist at dams and locks, especially in the more heavily traveled portions of the Western Rivers System. Two distinct approaches to this problem have been used. The first requires the construction of new, larger and better facilities. This not only includes the construction of locks and dams but also of larger barges, towboats with greater horsepower, etc. The second approach to the problem of congestion is concerned primarily with making more efficient use of existing (and, future) facilities. This includes possible changes in the way services are distributed at a lock, in the make-up of tows, etc. The Corps has commissioned numerous studies to determine how best to implement each of these approaches to the problem. 
The Corps has made significant strides in speeding the flow of traffic by improving waterway facllities. Among these are: double locks at dams, the construction of fewer but larger locks and dams on a channel, the standardization of sizes of both locks and barges, the greater use of large size barges and high horsepower towboats, the use of helper boats, etc. However, bullding new and better facilities is a very slow and expensive operation. often the increase in the volume of traffic that takes place between the beginning and the completion of a large construction project more than overshadows the improvements in capacity that have been made. Thus, the problem (long delays) which led to the construction has not been solved. The queues at the locks of the Inland Waterways System have been growing longer and as a result the waiting time has been increasing.

There is another difficulty with relying heavily on more and more construction to solve the problem of congestion. Every time that a new construction project is completed, it puts a severe limitation on the changes that can be made in the future. Once a construction is in place, in the event that future technology provides a means for obtaining substantial improvements in traffic capacity by means of radically different designs or construction methods then the nation has been forced into an obsolete, even though new, facility until a better system can be bullt reflecting this new technology. For example, if, after the locks on a channel have been constructed, it is found that substantial improvements in traffic capacity could have been achieved by changing the locations of several of the locks, then the nation is faced with the choice of replacing still usable facilities or living with a relatively inefficient system. Thus, new construction is a last resort. It is important that before construction takes place, all feasible non-construction approaches to the optimal operation of a waterway be investigated. 
Beginning in the early 1960's, there was just such a shift in the Corps' emphasis in its approach to the task of alleviating the congestion of the nation's waterways. Increased attention was given to the problem of making better use of existing navigational facilities, especially the locks and dams. Basically, this problem was attacked using two separate (but of ten complementary) tools - computer simulation and theoretical mathematics. A description of each of these tools and of the relation between them will be explored in detail in the remainder of this report. 


\section{The Operation at a Lock}

Most traffic along the Inland Waterways System consists of a flotilla of 6 to 15 barges lashed together and pushed by a towboat. The standard barge is 195 feet long, 35 feet wide and has a capacity of 1500 tons with a 9 foot draft. They are designed to carry solid cargo and are usually uncovered. There are also barges which carry liquid cargo. These tank barges have a capacity of up to 3000 tons. Towboats range in length from 100 to 200 feet and have a horsepower rating of anywhere between 2000 and 10,000 hp. The trend in recent years has been toward the more powerful towboats.

When a tow approaches a lock, it notifies the lockmaster (usually by radio) and then takes its place in a queue waiting to pass through the lock. At those locks at which there are two chambers, two queues are formed. If the chambers are of different sizes, it is common for the queue waiting at the smaller chamber to be smaller than the the queue waiting at the larger chamber. The tow captain can get in either queue to wait his turn. Until the tow passes the lock, it remains under the direction of the lockmaster who tells the tow captain where and when to move.

There will usually be another queue on the other side of the lock - vessel traffic headed in the other direction. The most common queue discipline is to alternately pass up-stream and down-stream vessels through the lock. Thus a vessel headed (say) down-stream enters the chamber from the up-stream pool. Water is pumped out of the lock until the water level in the chamber is the same as that of the down-stream pool. The vessel then leaves the lock and an up-stream vessel enters. Water is pumped into the chamber until the water level is the same as in the up-stream pool, and the vessel then leaves the lock. This procedure (one-up, one-down) is then repeated. It is customary to 
choose vessels from within a queue on a first-come, first-served basis and to Serve Opposing Queues Alternately. This is referred to in the literature as SOQA queue discipline. If vessels are not served according to the SOQA queue discipline then they are served in the order that they appeared at the dam. This is known as the First-In, First-0ut (FIFO) queue discipline. In a great portion of the literature it is not clear which queue discipline is being used. An entry of a tow into a lock begins when the tow captain is given permission to proceed from his watting position into the lock. When there is traffic in both directions on a river this waiting position must be sufficiently far away from the lock to permit vessels coming from the other direction to pass safely. This is called a long entry and can be as much as half a mile. When there is only one queue at a lock then the waiting position for tows in that queue can be just before the lock entrance. This is called a short entry.

As previously stated, traffic on each side of a lock is usually passed on a one-up, one-down basis. However, the lockmaster may expedite traffic by passing several vessels in one direction and then several vessels in the other direction. This is called an n-up, n-down queue discipline. When successive vessels travel in the same direction, the water level in the lock must be changed (raised or lowered according to the direction of travel) while it contains no vessel. This is called a swingaround or empty turnaround. In practice, the time lost during an empty turnaround is less than the time lost during a long entry. If there are to be $n$ passages through a lock in the same direction without passages in the opposite direction, then all but the first of these can use a short entry. Thus, more vessels can be passed through a lock when the n-up, n-down discipline is used than can be passed through in 
the same time when the one-up, one-down discipline prevails $5 /$. Although the n-up, n-down queue discipline leads to a shorter average waiting time per vessel than does the one-up, one-down queue discipline, nevertheless, some few vessels may be subject to unacceptably long delays.

Carroll, Rao and Wilson [16] state that the most effective queue discipline varies from lock to lock, depending upon the level of traffic, the tow mix, weather, etc. However, they present a table (Table 1 below) of average delay times for various combinations of queue discipline and number of tow arrivals per day, derived from a simulation analysis of Lock and Dam No. 27 on the upper Mississippi River.

Number of Tows Per Day

$\begin{array}{lrrrr}\begin{array}{l}\text { Oueue Discipline } \\ \text { First-come, first-served (FIFO) }\end{array} & \underline{11} & \frac{19}{28} & \frac{36}{19} \\ \begin{array}{l}\text { Serve Opposing Queues Alternatively } \\ \quad \text { (SOQA) }\end{array} & 5 & 22 & 63 & 199 \\ \text { Three-up, Three-down } & 5 & 23 & 46 & 120\end{array}$

Table 1. Average Delay Per Tow (in Minutes)

5 /The same phenomenon is observed at an intersection of two roadways controlled by a traffic signal. If only one vehicle is permitted to cross the intersection in any direction before the light changes, then the average waiting time per vehicle is very large. The minimum average waiting time per vehicle is achieved by letting traffic continue in any one direction until there is no queue waiting in that direction. Only then is traffic permitted to move in the other direction -and it will continue to move in that direction until that queue is empty. 
Entry time for a tow begins when the tow captain is given permission by the lockmaster to move from his position in the queue into the lock and ends when the bow of the tow actually enters the lock chamber. Chamber time begins when the bow of the tow enters the lock, continues while the tow is actually in the chamber and ends when the stern of the towboat passes the other side of the lock. Exit time begins when the stern of the towboat leaves the lock and ends when the tow has cleared the lock area (so that a tow traveling in the opposite direction can begin its entry).

If an entire tow can be accommodated into a lock chamber without any changes in the configuration of the flotilla then the passage is called a single lockage. Sometimes an entire tow can fit into a lock chamber, but only after the configuration of the flotilla has been changed. Usually the towboat must be moved from its normal position behind the barges to a position alongside them. The towboat retakes its position behind the flotilla of barges on the far side of the lock and the flotilla then continues its journey. Such a passage is called a setover lockage. Clearly a setover lockage requires more time than a single lockage. When a tow is too large for either a single lockage or a setover lockage then the passage of the tow must be made in several stages. The flotilla of barges is broken up into two (or more) parts and each part is passed through the lock separately. When all of the barges have passed to the other side of the lock, the tow is reconstituted and proceeds on its way. This is called a double (or more) lockage and requires substantially more time than either a single or a setover lockage. Many factors beside tow size affect the speed with which a tow can be passed through a lock. Foremost among these are: the physical attributes and the condition of the lock itself and of the nearby waterway, the tightness of the fit of the flotilla in the chamber, the horsepower of the towboat and the weight of the load in the 
barges, the currents in the river, etc. DeSalvo and Lave [31] and Kooman and DeBruijn [53] have discussed a long list of other factors involved in tow delays.

Carrol1, Rao and Wilson [16] have presented a table (Table 2 below) of typical locking times (broken into its three components) for the various lockage types at a $600 \times 100$ foot lock.

\begin{tabular}{lccccc} 
Lockage Type & Total & & $\begin{array}{c}\text { Entry } \\
\text { (Long) }\end{array}$ & Chamber & Exit \\
\cline { 2 - 3 } & $35-45$ & $8-12$ & $23-27$ & $4-6$ \\
Single & $105-135$ & $10-22$ & $90-106$ & $5-7$ \\
Double & $50-70$ & $8-16$ & $37-47$ & $5-7$
\end{tabular}

Table 2. Typical Locking Times (in Minutes)

In 1970 , in an attempt to reduce the locking time for double lockages, the Corps placed an auxiliary towboat at Lock and Dam No. 26 on the upper Mississippi River (Rao [69]). This dam, just above St. Louls, is one of the most time consuming bottlenecks in the Inland Waterways System. The boat (called a switchboat) was used to pull the first part of a flotilla of barges of a double lockage out of the chamber and to tow it to a mooring where it could wait for the remainder of the tow without interfering with an entry into the chamber from the opposite direction. The towboat and the second part of the flotilla of barges then passed through the lock and the tow was reconstituted. This procedure reduced the chamber time for double lockages from an average of about 93 minutes to about 69 minutes. 
When a tow is barely able to fit into a lock chamber (e.g., nine 195 foot long, 35 foot wide barges lashed together into a flotilla measuring 585 feet by 105 feet, fitted into a standard 600 foot long, 110 foot wide chamber) great care must be taken in order not to damage either the tow or the lock facility. Clearly this need for caution tends to increase the time of the lockage. This is a problem which will become increasingly more serious as the size of both barges and towboats continues to grow. 
5. Barge Traffic on the Inland Waterways System

The total length of the commercially navigable waterways of the United States is currently 25,543 miles. Of this total, a draft of at least 9 feet is maintained on 15,675 miles. Sufficient draft for navigation (usually 9 feet) is obtained by a system of 280 locks and dams containing 325 chambers on 44 waterways $\%$. These locks provide lifts of up to 105 feet. The main chamber at a lock varies from a minimum of $120 \times 30$ feet to a maximum of $1200 \times 110$ feet $[79]$.

The trend in recent years has been toward the construction of larger barges and more powerful tugboats. Immediately after World War II, the standard solid-cargo barge was 175 feet long, 27 feet wide and 10 feet deep. The jumbo dry-cargo barges of today are 195 feet long, 35 feet wide and 11 or 12 feet deep. Tank barges (for liquid cargo) range from 200 to 300 feet long and are about 50 feet wide. On locking rivers tows usually contain between 6 and 15 barges. On open waterways, tows having 40 barges are common. The increasing size and power of the inland waterways fleet is illustrated in Table 3 .

\footnotetext{
6/These figures include the Cross Florida Barge Canal which is not operational.
} 
Type of Vessels

Self-Propelled

Towboats and Tugs

Number of vessels

Horsepower

Non-Self-Propelled

Dry-Cargo Barges and Scows
Number of Vesseis
17,527
23,164
32.16
Cargo Capacity (net tons)
$19,710,605$
$27,135,336$
37.67
Tank Barges

$\begin{array}{lrrr}\text { Number of Vessels } & 3,420 & 3,623 & 5.94 \\ \text { Cargo Capacity (net tons) } & 7,486,718 & 8,510,016 & 13.67\end{array}$

Table 3. Towboats and Barges of the United States (1971-1975) /

The largest portion of the nation's tows operate in the Mississippi River System and the Gulf Intracoastal Waterway. Table 4 below presents the distribution of both towboats and barges in the Inland Waterways System.

7 /Table 3 is a portion of a table provided by the American Waterways Operators, Inc. 


\section{Mississippi River \\ Type of Vessels System and the Gulf \\ Atlantic, Gulf \\ Great Lakes \\ Intracoastal Waterway \\ and Pacific Coasts \\ System}

Towboats and Tugs

Number of $\frac{\text { Vessels }}{4}$

$$
2,541
$$

1,554

145

Horsepower

$3,574,850$

$1,860,026$

151,015

Dry-Cargo Barges and Scows

Number

18,049

4,917

198

Cargo Capacity

(net tons)

$22,255,050$

$4,565,839$

314,447

Tank Barges

\begin{tabular}{|c|c|c|c|c|}
\hline Numbe & & 2,979 & 577 & 67 \\
\hline Cargo & $\begin{array}{l}\text { Capacity } \\
\text { (net tons) }\end{array}$ & $6,295,236$ & $2,056,813$ & 157,967 \\
\hline
\end{tabular}

Table 4. Towboats and Barges on the Inland Waterways System (1975)

Thus $59.9 \%$ of the nation's towboats, $77.9 \%$ of the nation's dry-cargo barges and $82.2 \%$ of the nation's tank barges operate on the Mississippi River System and the Gulf Introcoastal Waterway.

In conjunction with the recent trend to build larger barges and more powerful towboats the Corps has been replacing locks of small chambers ( $600 \times 110$ feet) with larger chambers (1200 x $110 \mathrm{feet})$. In addition, newer locks have a higher lift than the older ones. Thus fewer locks are necessary on a waterway. For example, the Corps' modernization program for the Ohio River provided for the replacement of 46 existing locks with 19 larger locks. 


\section{Attacking the Problem}

The Army Corps of Engineers has been striving since early in the nineteenth century to maintain and improve the nation's navigable waterways. Until the period just after World War II, the major thrust of the Corps' efforts was in channel improvement and the bullding of new and larger facilities. With the growing congestion on the inland waterways caused by the rapid expansion of waterborne freight traffic, the Corps was forced to seek additional ways in which to improve service. Previously there had been little effort to analyze the locking procedures and use these analyses to speed the flow of traffic. In the 1960's, theoretical studies of lock operations were initiated. Various local Corps offices had conducted systems analyses concerning their particular operations since 1968. Shortly thereafter it became apparent that there was need for a more integrated planning and development program. It was necessary that this program be undertaken within the context of the total United States transportation system and economy. In 1970, a task force was set up by the Office of the Chief of Engineers to determine what role the Corps should take in the general problem of navigation systems analysis. The report of this task force in 1973 led to the institution of the Inland Navigations Systems Analysis (INSA) program.

INSA is a planning capability. It is an integrated system of models, data, and planning procedures developed to explain, predict and plan for U.S. Inland waterways transportation. It is designed to help the Corps achieve two goals: 
- Operate the current inland waterways system as efficiently as possible,

- Select the best size, location and timing of inland waterways improvements.

To achieve these goals, INSA uses its models, data and planning procedures to

- Forecast commodity flow,

- Predict modal share of traffic,

- Simulate and monitor inland waterway transportation,

- Predict economic impact of inland waterway improvements.

The INSA simulation models will be discussed in detall later in this report.

Interest in analyzing lock procedures and in using these analyses to speed traffic flow coincided in time with the emergence of large-scale electronic computers. The availability of these computers made it possible for the first time to perform elaborate simulations of a waterway. Although simulations include the constructing of physical models, usually in miniature, and the actual manual manipulation of them [4], the vast majority of simulations are done abstractly on a computer. For mathematical simulation of any system, a computer program must be written which describes the essential features of that system. In addition, demand and capacity data are required, as well as some start-up information describing the condition of the system before the simulation begins. All of this must be entered into the computer in a form compatible with the simulation program. The computer then operates on all of 
the stored information, using the program provided, and produces the performance statistics of the operation. Hopefully, these results are similar to the actual performance of the system being modeled.

The main advantages of computer simulations are speed and the relatively low cost of testing alternative scenarios. The disadvantages of computer simulations are

- Difficulty in defining and writing a program which adequately captures the essential features of the system being modeled,

- Necessity for introducing an element of randomness into a problem so that a simulation often cannot be exactly duplicated,

- Necessity to search for optimal solutions and the difficulty of recognizing whether the simulated operational strategies could be further improved by investigating yet another set of parameter values,

- Inflexibility of a particular simulation program, that is, making a minor change in the scenario or introducing additional parameters to a computer program which was not designed to accomodate them would require extensive changes in the computer program.

At about the same time that computer simulations were being introduced as a method for modeling traffic on a waterway, the first attempts were being made to use queueing theory as a tool with which to model the operation of a lock. Queueing theory is a branch of applied mathematics developed early in the twentieth century, primarily to study congestion in telephone circuits. As in, the simulation technique, the essential features of the system must be identified and incorporated into the model. The task of the mathematician is to express these features in the form of equations, or some other mathematical expression, and then to provide a solution. Once the mathematical solutions are found, it is usually very easy to obtain directions for the optimal use of 
the system being modeled $8 \%$ The main advantages of a theoretical mathematical solution are:

- the parameters of the system can easily be varied over a broad range,

- sensitivity to changes in the parameters can be studied,

- the optimal solution is usually identifiable and readily available,

- results can readily be duplicated.

The major disadvantages are:

- the difficulty in expressing the essential features of the system mathematically,

- the difficulty in solving the mathematical formulation once it has been obtained.

It is generally agreed that when a viable theoretical approach can be found, it is superior to simulation as a tool.

8 /When the features of the system are probabilistic, rather than deterministic, it usually happens that the solution obtained yields the optimal onthe-average use of the system, rather than the optimal use obtainable from a hypothetical policy that could somehow predict and allow for all random fluctuations. Clearly the lock and dam scenar o falls into this category. 


\section{Simulations (The Early Years)}

While the present study is concerned with the state-of-the art in estimating lockage delays and lock capacities, it is not feasible to ignore the body of work which deals with peripheral areas of waterways traffic but which, nevertheless, acted to stimulate research devoted specifically to locks and their operations. The first attempts to simulate traffic on a waterway were made at a time when the computer was just beginning to be a serious tool in scientific research. The computer was expensive to use, had only a small fraction of the capability it was later to have and computer time was not easily avallable. Early theoretical studies of lock and waterway capacity were generally small scale, using a minimal amount of computation and requiring limited amounts of data.

In 1954, the Melpar Corporation was commissioned by a private company which operated tows on the Ohio and Mississippi Rivers to Improve the company's profits. In a paper which was the outgrowth of this projects, O'Brien and Crane [66] devised a Monte Carlo simulation of the fleet movements of the company's tugs with the aim of lmproving performance by keeping towboats and barges "busy". The simulation was to be performed without the use of electronic computers. The data required for the simulation were the number of avallable barges left at each port served by the company and the number of days barges were held before they were returnable as "emptles". (All freight traffic was In one direction.) A table of random numbers was used to obtain distributions for input into the simulation. However, in order to simplify calculations 1 was soon decided to replace these distributions with thelr average values. This resulted in only minor changes in the output of the simulation. Although the company's traffic passed through a number of locks, the work by 
O'Brien and Crane did not consider either the operation of the lock and dam scenario or the movement of traffic in a waterway. However, their paper did seem to stimulate a long 11 st of more theoretical and broadly based studies. It is interesting to note that O'Brien and Crane's paper had no references.

It has long been recognized that in order to determine the efficiency of operations at a lock, some theoretical maximal capacity must be postulated. Then, the actual capacity achieved at that lock can be compared with the theoretical capacity to obtain a measure of efficiency. In 1966, Bottoms [6] defined a maximal tonnage capacity for a lock in terms of the lock size and the lockage times. He also defined the practical tonnage capacity and showed that the efficiency (i.e., the ratio of practical tonnage capacity to maximal tonnage capacity) was about the same for all of locks he investigated. Since the efficienty was consistently in the $25 \%$ to $32 \%$ range, he concluded that much more tonnage could be gotten through a lock using the present facilities. In 1967, Schultz [76] continued the work of Bottoms but showed that the capacity of a lock depended on a number of factors which Bottoms had ignored. For example, the stretch of waterway leading to the lock, the depth and the breadth of the floor of the channel, the hydraulics of the lock, etc. all influence the true maximal tonnage capacity. Schultz introduced a graphical method, using scale model paper cutouts, to analyze the capacity of a waterway.

Since these pioneering efforts, there has been a steady stream of increasingly sophisticated papers treating the theoretical maximal capacity (in tonnage, in cost-benefit, etc.) of a lock and attempting to improve lock efficlency by non-construction methods. In 1ts bare-bones form, the capacity of a lock (in vessels per time, period) is determined as follows: 
(i) Find the mix of vesse1-types $n_{1}, n_{2}, \ldots$

(ii) Find the locking time for each type of vessel in the mix, $t_{1}, t_{2}, \ldots$

(iii) Find the time between vessels, $t_{0}$,

(iv) Calculate the total time needed to pass a mix of vessels through the lock, $t=\left(t_{1}+t_{0}\right) n_{1}+\left(t_{2}+t_{0}\right) n_{2}+\ldots$

(v) Calculate the average time required per vessel.,

$$
\bar{t}=t /\left(n_{1}+n_{2}+\ldots\right)
$$

(vi) Calculate the number of vessels, $\mathrm{N}$, which can pass the lock in a time period $T$,

$$
N=T / \bar{t}
$$

A simple change in step 1 is needed if capacity is to be expressed in tonnage per time period. The input data for this bare-bones capacity model is

- the vessel mix,

- the locking time for each type of vessel,

- the time between vessels.

When capacity of an existing lock is being determined, the needed data can be obtained by observations made at the lock. This is not possible when the lock under consideration has yet to be built, or when new procedures are contemplated at an existing lock then. To obtain input for the model in these cases a study is necessary based both on the data available at similar existing locks (if any) and on estimated date derived from the contemplated features of the specific lock under consideration.

Once the bare-bones model has been established, improvements in the model can be made in several ways:

- distinguish between situations which have been lumped together in the bare-bones model and treat them separately, e.g., up-stream and down-stream vessel mix, locking time, etc.; lockage in winter and in summer, in darkness and in light, etc. 
- Incorporate into the model distinguishing features of the lock being considered, e.g. the depth of the chambers, the separation of the chambers (when there are more than one), the speed, currents and geometry of the river, the capabilities of the hydraulics system, etc.

- consider the effect of treating the traffic sequentially rather than lumped by the proportion in vessel mix.

In 1975, in the Hague, Kooman and DeBruljn [53] presented a long, detalled paper giving an algorithm for finding the capacity of a lock. It was a refined version of the bare-bones model described above. Although this model was developed for study of the inland navigational system of the Netherlands, it can be applied in the United States as well. Among the particular aspects of the lock facility and traffic mix considered in this paper are:

- the wet cross sections of both the upper and lower gates,

- the distance for a long entry,

- the dead weight of each vessel,

- the vessel length,

- the vessel utilization ratio,

- laden and unladen vessels.

Using their model for lock capacity, Kooman and De Bruijn estinated the delay time at a lock in terms of the ratio of volume to capacity. In general they used average values of the data in their simulation. According to Kooman and and De Bruljn,

For a given lock the duration of successive lockages varies in practice under the influence of the number of vessels to be locked and the actual exit and entry times per vessel. These quantities are not, however, constant but are in turn a function of such different variables as the volume of traffic, sizes of vessels, vessel utilization, type of vessel, the way vessels are navigated, etc. A simulation of the locking process on the basis of the variable lockage time, taking into account all the important influencing factors, is extremely complicated. No computer program is so far available for an expanded simulation of this kind. 
Apparently, the earliest application of $c$ aputer simulation to the operation of a lock was made by Joseph Carroll [9] in 1965. Working under the auspices of the Tennessee Valley Authorfty, Carroll constructed a Monte Carlo model of the Pickwick Lock on the Tennessee River. The Plckwlck Lock is a single chamber lock and so represents the simplest locking situation. At the initial stage of the simulation, no attempt was made to integrate the operation of the single lock into the entire waterway system of which it is a part. (A simulation in which the whole of the system is included in the model, in the full spirit of a "systems analysis", is considerably more difficult to construct.) Carroll's earliest model contained provisions for single, double, triple and setover lockages. In addition, the program considered entry times (both long and short), exit times and times for empty lockages. Tow arrival patterns were part of the input to the model and both random and regular arrivals were used. The output of the model was the lockage delay and idle times of each tow as well as the number and types of tows processed. The output of the model was compared with data obtained from the Plckwick Lock. This paper was the first in a long series which culminated in the INSA program ten years later.

At about the same time that Carroll was constructing his model of the operation of a lock, Howe [48], at Resources for the Future, Inc. (RFF) modeled the speed of tow as a function of channel depth and barge-flotilla configuration. As an outgrowth of these two models, the first systems model was developed jointly by RFF and the Pennsylvania State University [10]. This model simulated the movement of shallow-draft tows through a single straight waterway. The model could accommodate up to 10 locks, each with one or two chambers, 20 ports and 10 delay points 'zhannel restrictions). The input for this simulation consisted of 
- Tow characteristics (horsepower, tonnage, average draft and flotilla configuration),

- tow itineraries (sequences of points visited in traveling through the system),

- physical attributes of locks, channels and delay points,

- operating characteristics of locks (in the form of frequency distributions for up to 8 distinct locking time components for each chamber in each direction).

The arrival times of the tows at the origin points (which, in this model, were restricted to the two end points of the channel) were generated randomly by means of a Poisson process. The movement of each tow in the channel was based on the speed attainable by the tow (obtained from the RFF model) and the passage time (entry, lockage and delay times) of the tow through the lock (obtained from Carroll's Pickwick Lock model). The output of the model was a description of the movement of each of the tows until it reached its preassigned destination (or until the model run was terminated). From this, a large variety of statistics describing what took place in the channel could be compiled. These include:

- the number of tows and barges processed at each lock,

- delay times,

- tonnages and tonnage-miles,

- the number of single and multiple lockages,

- average queue lengths.

Finally, the adequacy of the model was judged by comparing its output with actual data collected by the Corps of Engineers on a portion of the Ohio River. 
The RFF-Penn State model described above was refined and generalized at the Pennsylvania State University by Carroll and Bronzini in 1971 [12]. It was intended that the new model be applied to a Y-shaped channel (rather than simply a stralght channel) based on a portion of the Upper Mississippi River contalning 3 locks and a portion of the lllinols River containing 7 locks. In addition, limits on the number of different tow characteristics and on the travel itinerarles were expanded. Also, it was required that the number of towboats and barges which enter a port be substantially equal to the number which leave. While the model was being prepared, it became evident that the construction of the input data was in itself a difficult problem. For this reason, the model was broken into two parts and a separate model was used for the generation of traffic. This first part, called TOWGEN, consisted of a program to generate a time-stream of tows from the various origins (no longer restricted to be the end points of the channel) to their destinations. The Input to TOWGEN consisted of :

- An origin-destination (O-D) tonnage matrix for each commodity,

- a table of barge data, showing commoditles carried, average loading and commodities backhauled by each type of barge,

- an $O-D$ mileage table,

- a frequency distribution of flotilla size and towboat horsepower for each commodity

- cost functions for each type of barge.

Tows were generated stochastically within the computer. The number and placement of empty barges required to support the assumed commodity flow were computed and made a part of the waterway traffic.

In the second part of the model, the tow generated by TOWGEN re put through a waterways simulation program (WATSIM) taking them from their point of origin 
to their destination. In addition to the output of TOWGEN, the input for WATSIM consisted of :

- parameters specifying the particular program options to be used, including the attainable speeds in the channel, taken from Howe's RFF model,

- frequency distributions for the components of locking time,

- a description of the waterway including ports, locks, delay points and channel junctions.

The output of WATSIM consists of 12 tables describing the traffic that the model has created. Typical outputs available from the program are:

- The number of barges and tows of each type originated and terminated at each port,

- The number of tows and barges and total tonnage passing through each lock,

- Total and average delay and process time at each lock,

- Maximum delays and queue lengths at each lock,

- Number of single and multiple lockages and locking times for each chamber at each lock,

- Frequency distributions of tow delays and headway spacings,

- Instantaneous and cumulative inventories of towboat and barge utilization,

- Sumary of system delays.

The WATSIM model accommodated up to 30 ports, 20 delay points and 75 different lock chambers distributed among 30 different locks. The waterway modeled by WATSIM was permitted to have up to 5 branches. Ten types each of barges, tow horsepowers and flotilla sizes were allowed. The programs were written in FORTRAN IV(G) and run on the IBM $360 / 67$ at Pennsylvania State University. 
One critical parameter for the WATSIM model is the amount of time required for a tow of a given type (number, size, load and configuration of barges, size and horsepower of towboats, etc.) to pass through a given type of lock (size of chamber, single or multiple chambers, switchboat, etc.) by means of a given type of lockage (single, double, setover). As part of the Pennsylvania State University simulation, a separate model (LOKSIM) was developed by Hayward [42] in 1971, under the direction of Carro11, in order to better estimate this parameter and, at the same time, provide additional flexibility in the model. LOKSIM permits up to 3 chambers at a lock, various chamber assignment and queue disciplines, and a mix of pleasure craft and commercial vessels. After its development, LOKSIM was integrated into the TOWGEN-WATSIM package.

In August 1971, the Pennsylvania Transportation and Traffic Safety Center (PTTSC) of the Pennsylvania State University submitted a 6 volume report about the TOWGEN-LOKSIM-WATSIM package (to be referred to as the PSU-COE model) to the North Central Division, Army Corps of Engineers. Volumes 2 [39], 3 [8] and 4 [42] are devoted to in-depth detailed descriptions of the WATSIM, TOWGEN and LOKSIM models respectively. Each volume lists the data requirements and other inputs, the operation and the outputs of the model and includes a discussion of the testing that the model had undergone. Volume 1 is a summary report of the entire project and has a chapter devoted to two applications of the program made by PTTSC to study alternative designs for lock and chamber configurations. The first of these was to a portion of the Ohio River (described in greater detail in Volume 6 of the report $9 /$ ). The second

9 /Volume $V,[70]$ of the PTTSC report is concerned with navigation on a deep draft waterway and will be discussed later. 
application was to the 10 lock subsystem of the Illinois and upper Mississippi Rivers which was the original impetus for the projects. In addition, the North Central Division, Army corps of Engineers used the TOWGEN-LOKSIM package in a separate study of the upper Mississippi River. These 3 applications provided a verification of the versatility and usefulness of the package.

The waterway system simulations described above formed a series in that each paper built on the previous research. However, at about the same time, there were a number of isolated simulations of locked river being developed in various parts of the world. In 1969, in France, Rousselin [74] studied the capacity of the upper Seine River. He presented a theoretical method for determining the maximal capacity of a navigable waterway. The optimal economic capacity was obtained by multiplying various factors of the maximal theoretical capacity by reduction coefficients. However, Rousselin determined that a computer simulation of the operation of the waterway would give a more precise estimate of the optimal economic capacity than does the "classical method" previously described. In 1970, Dunan and Coutheillas [33] continued the work of Rousselin and described the simulation model in detail. The model is small scale, having a maximum of 4 locks (though they may be of different sizes) and not permitting branches in the channel. In addition to a flow diagram of the model, Dunan and Coutheillas provided

- a list of inputs needed for the model (location and dimensions of the locks, times required to fill and empty the chamber, number and types of tows, etc.)

- a list of outputs (the number and categories of the vessels passed, average time of passage, total number lockages, etc.).

No mention is made of the model ever being tested by comparing its output with real data. These papers do not present any advances over the PSU-COE model. 
In 1967, in West Germany, Leutzbach and Lenz [58] developed a model of a single chamber lock which combined a small amount of queueing theory with a computer simulation. They showed that for a waterway with Poisson arrivals of tows, the average waiting time predicted by the model was the same as that given by queueing theory. An interesting feature of this model is that the lock can be held open to await an arriving tow for a specifled period of time.

All of the models that we have discussed thus far are for vessels traveling in a shallow-water channel. There are a number of other studies dealing with deep-draft navigation and these will be discussed shortly. Undoubtedly other shallow-draft simulation models have been constructed in various parts of the world. However, the PSU-COE simulation models appear to be more detailed, more versitile and more useful than those developed elsewhere. According to the INSA report, Volume 5 [80]

In general, forelgn models were developed to satisfy the needs of particular project studies, and there has been little work on generalized models. These models have not been relied on in U.S. efforts, probably because of lack of domestic exposure, language barriers, computer differences, and differences in navigation conditions and operating practices. Also, models directly applicable to U.S. waterways were developed at about the same time as the foreign models.

In the previous paragraphs I have endeavored to show the path along which simulation of shallow-draft waterways developed through the early 1970's. During this period, parallel research projects concerning deep-draft waterways were taking place. The problems encountered in studying deep-draft waterways are quite different from those met in modeling shallow-draft waterways. For example, traffic in deep-draft waterways consists largely of ocean-going ships. Thus the many-facted problems engendered by towboats and barge flotillas do not apply to deep-draft waterways. On the other hand, deep-draft 
waterways present a number of problems $10 /$ of their own (e.g. the existence of significant tides, the use of tugs, etc.). As stated in the INSA report, Volume 5

the substantive differences in the salient characteristics and operating procedures of the two systems account for the lack of direct model transferability.

A number of models were developed in the period 1968-70 to study interoceanic ship traffic through the Panama Canal. In 1969, A.T. Kearney \& Company [1] developed a sea-level canal simulation, written in the SIMSCRIPT programming language in order to evaluate the effect of nonstructural improvements on the canal's capacity. This model contained several novel features. Inputs included ship size, arrival rates, weather conditions operating restrictions, lock staffing and equipment, and scheduled down-time for maintenance. Outputs included lock utilization, tug requirements and traffic congestion.

A simulation based on a proposed sea-level canal in Panama was developed by Harrison [41] in 1969 for the Waterways Experiment Station (WES) of the Army Corps of Engineers. This program was written in FORTRAN and moved ships through the canal by computing their maximum safe speeds in terms of canal geometry and each ship's individual characteristics. The effect of tides was incorporated into the model and various tidal ranges and canal geometries were used.

The Welland Canal connects Lake Ontario with Lake Erie. The elevation of Lake Ontario is 326 feet higher than that of Lake Erie. This 326 foot difference is made up in a 7 mile stretch of the 27 mile Welland Canal. This portion of the canal contains 7 locks with an average lift of 46 feet. In fact, locks

$10 /$ Generally, treatments of these problems have been of a less mathematical nature and so are of less interest in this study. 
4,5 and 6 are constructed so that a ship sails directly from one lock right into the next. There is an eighth lock which compensates for the fluctuating levels of lake Erie. The Welland Canal runs parallel to the Niagara River and so permits ocean-golng vessels to bypass Niagara Falls.

In 1965 Luce and Sandor [59] studied the Welland Canal with a view to increasing its effective capacity. In examining the operation of the canal they concluded that the major causes of congestion were

- Irregular arrivals leading to an effective capacity of less than $75 \%$ of the maximum capacity,

- Interruptions in service due to weather conditions and accidents, etc.,

- one particular lock (Lock 7) was a severe bottleneck,

- the entries to the lock were too long,

- ship captains unnecessarily took too much time for each lockage, In order to increase the efficiency of the waterway, they recommended that

- traffic traveling toward Lock 7 be given priority over traffic traveling away from the lock,

- fast vessels be given priority over slow vessels,

- ship captains be made aware of the importance of the short time period (about 5 minutes) that they waste during a lockage,

- lock and dam priorities be arranged so that when bad weather is expected, those operations which can continue may do so (e.g. heavy vessels are less susceptible to bad weather than are light vessels.

- special rules to be established to apply when traffic is essentially in one direction, 
- there be greater communication between locks, leading to dynamic graphic display models of all traffic on the canal being maintained at each lock.

The implementation of these recommendations was able to reduce the lock cycle from 100 minutes to 80 minutes. Although this paper is devoted solely to the Welland Canal, it contains a number of features which should be of general interest. The two unusual queue disciplines (fast one first, and heavy one first) which were successfully implemented on the Welland Canal, do not seem to have been considered elsewhere. In addition, the authors emphasize the sensitivity of the number of lockages per day and the queue length to the time required for an individual lockage. This emphasis appears to be a very useful outlook on waterway research and should be more widely employed than it is.

In conjuction with the study of the Welland Canal by Luce and Sandor, the Kates, Peat, Marwick \& Company developed a simulation program, written in ALGOL. The St. Lawrence Seaway Authority (SLSA) rewrote this program in FORTRAN in 1968 [77] and made a number of improvenents which permitted the model to be applied more widely. In this model, locking times were based on the specific ship, crew and lock crew characteristics.

As previously stated, the fifth volume of the PTTSC report was concerned with a deep-draft waterway. Rea and Nowadig [70] developed a simulation model for a multiple channel deep-draft navigational system. The impetus for this work was a proposed new canal paralleling the Welland Canal, but on the U.S. side of the Niagara River. The earlier SLSA model was incorporated into this one and several additional features were added. Since there would be two channels connecting Lake Ontario with Lake Erie, a means of assigning vessels to one or the other would be necessary and this became an important part of the model. 
Another feature of this model was a provision for a lock to remain open for a fixed period of time to await the arrival of an expected vessel. (This capability also appeared in the model developed by Leutzbach and Lenz [58] in 1967 in West Germany.)

In 1973, Carroll, Rao and Wilson [15] introduced a new deep-draft simulation model called NETSIM. It was an expanded version of the one Rea and Nowadig had developed two years earlier for the proposed canal parallel to the Welland Canal. The aim of NETSIM was to model the entire Great Lakes seaway system. The following features were added to the 1971 package:

- the passage of a vessel through the entire Great Lakes seaway system could be simulated,

- an O-D matrix for each commodity carried along the system,

- a dynamic, real-time algorithm for scheduling vessels in accordance with customer demand for transport.

The program language was changed from IBM General Purpose Simulation System (GPSS) used by Rea and Nowadig to SIMSCRIPT.

Several foreign studies of navigation on deep-draft waterways have been made. In 1969, Nishida, Watanabe and Eguchi [65] constructed a simulation of traffic on the Uraga Channel, connecting Tokyo Bay with the Pacific Ocean. The Uraga Channel is an open waterway. However, vessels entering the area are given very specific instructions as to which route to take. The Ministry of Transportation proposed increasing the capacity of the Urage Channel by enlarging and straightening the current routes and by changing port regulations. This paper provides a simulation of traffic to examine the route improvement plan. A detailed flow chart is provided, together with a list of inputs and outputs. 
In 1972, Deazeley and Wilson [28] described a simulation they performed to model the Bristol Channel as a closed waterway. An interesting feature of this model is the assumption that when a tow appears which is not large enough to fill the chamber a lockage will not take place until a second tow appears to fill the chamber. Inputs for the model include:

- the density of trafic,

- tidal conditions,

- ship-size characteristic patterns,

- the discipline at the lock,

- the size of a lock or set of locks,

- the number of locks,

- the service time at a lock.

The output of the simulation is a curve of the mean waiting time per ship as a function to the traffic density. It is pointed out that the mean waiting time per ship will not occur when traffic is lightest because, in such a situation, ships may have to wait for a lockage until the chamber contains enough traffic. The program was written in ALGOL but no details of the flow chart are given.

In 1971, Matlin, Gokhshteyn and Kunakhovich [60] presented a comprehensive discussion of an integrated deep water navigational system in the European part of the USSR. This report was designed to serve several purposes. One was that the work would serve as a text for students at Soviet universities. According to the authors

The development of the river network and improvement of the navigation conditions on the rivers of the USSR are taking place primarily on the basis of all around utilization of the water resources: the construction of hydro-engineering complexes on the navigable rivers to generate electric power and simultaneously increasing the navigation dimension; construction of canals used for irrigation or water supply with provision 
of navigable conditions on them; the creation of reservoirs to regulate the runoff and at the same time maintained for navigation purposes, and so on. In addition, in our country there are no canals or supporting structures and none planned which do not also serve for the purposes of land improvement, water supply and the generation of electric power. [sic]

In this paper, there are many descriptions of the waterways of the Soviet Union and much discussion of the specific commodities which will have to be shipped along the country's waterways. However, no mention is made of simulations, or, models of any kind, being used to obtain indications of optimal use of the waterways. Very little concern is given to problems of delay time or of different lock disciplines and operating procedures. All of the references in this paper are to Soviet publications and appear to be of the same type as the paper itself.

In addition to those research projects which have been described above, there were undoubtedly many other papers written both in the United States and abroad during this period (until about 1973) describing analyses of navigation on inland waterways. The typical model appearing in the literature consisted of a bare-bones flow diagram of a computer program, coupled with observed data used to provide numerical values for the model's inputs. The majority of these models were aimed at one particular lock or channel which the authors were interested in. One striking feature of this early literature is the infrequency with which one author (or team of authors) cites the work of other authors. It seems plausible to assume that very few authors were familiar with previously-made models. It then follows that very similar models are repeatedly independently discovered. Sometimes very broad, general remarks appear by an author claiming that his model is better than (unnamed) others. This claim is seldom if ever substantiated. For example, in 1972, Deazeley and Wilson [28] stated that 
so far as the writers are aware this is the first time a simulation model of such versatility has been devised for the shipping traffic.

The only reference in the paper was to an earlier paper by Deazeley. Each author lacked the sense that his work is a single step along a long path. This can be seen by how few people described the workings of their model in terms subsequent authors could build on.

This section would not be complete without mentioning a simulation of a very different kind which was conducted by Armstrong [4] in 1970 as part of the project considering replacement of Lock and Dam No. 26 on the upper Mississippi River. In order to test the desirability of each of several possible major construction projects, a physical model was constructed on a scale of 1 to 120 to reproduce a 6.7 mile portion of the upper Mississippi River. Several alternate lock and dam configurations were constructed which could be fitted into the scale model in various combinations. The effects of each of these on the flows and currents within the miniature waterway were measured. Two model towboats with remote control were added to the systen to determine the ease of maneuvering for each configuration. The actual maneuvering of the model towboats was done by a group of 17 towboat pilots who had spent many years on that portion of the Mississippl River and were familiar with the river and with the operation of tows and who were invited to participate in the project. After maneuvering the two towboats through the various configurations, the opinions of the pilots were solicited and then tabulated. 


\section{Simulations (Part 2)}

Up to 1973 a large number of simulation models of varying sizes, and scopes were developed in the United States and abroad. After 1973, very few new models were constructed. Instead, navigation research turned toward the unification, refinement and expansion of existing models. Also, the emphasis changes from models geared to specific waterways (or portions of specific waterways) to models which could be used to simulate widely differing navigational systems. After the PSU-COE package was accepted by the Waterways Experiment Station (WES) of the Corps of Engineers, Daggett, Ankeny and Eiland [22] in 1973 expanded WATSIM into a more sophisticated program (called WATSIM IV) by adding a number of features which reflected traffic conditions on the Gulf Intracoastal Waterway. This constituted a new area of application. The PSU-COE package had been aimed primarily at the Western Rivers System and the Great Lakes System. The major innovations of WATSIM IV were:

- the provision for multiple lockages,

- the provision for open lockages (that is, lockages in which both of the locks are open at the same time).

The long period of development through which the PSU-COE model passed culminated in 1976 in the Inland Navigation Systems Analysis (INSA) [79]. The INSA program is an integrated system of models, data and planning procedures. It was put together by the Corps of Engineers in order to provide a comprehensive model with which to examine the effects on waterway capacity and on tow delays of changes in construction, regulation, operations, etc. Although the INSA program was a direct descendent of Carroll's and Howe's trallblazing models of 1965, INSA also contained a systhesis of a great volume of research 
on waterway navigation from all parts of the world. Its aim was to provide a general-purpose, state-of-the-art model, together with directions for obtaining the data necessary to drive the model and a study of the sensitivity of the model to the data. Among the major improvements incorporated into the INSA program from the earlier PSU-COE model and the WATSIM IV revision are:

- the separate program (TOWGEN) converting commodity flows into vessel generation was replaced by commodity flows being fed directly into the simulator; then a stored representation of port operations (barge loading and unloading, flotilla assembly, dynamic tow dispatching, etc.) was used to generate vessel traffic,

- the ability of the model to simulate navigational systems of arbitrarily large size,

- greater flexibility in barge mix, type of lockage, flotilla size, etc.

- the avallability of various lock queueing disciplines,

- the assignment of traffic among parallel routes when they are available,

- the inclusion of pleasure craft into the model,

- the monitoring of a greater number of output variables,

In addition, computer languages especially designed for use in traffic simulation were employed. The computer language used by INSA was SIMSCRIPT II.5.

Since they became available, the WES TOWGEN-WATSIM IV model and the INSA program have been used for numerous studies on various waterway systems. One important application of the WES model was made in 1975 to the long-standing problem of the proposed replacement of Lock and Dam No. 26 on the upper 
Mississippi River near St. Louis, Missouri [79]. Other studies were made on the Illinois River, the proposed Red River waterway and the Black Warrior River System in Alabama. By 1976 over 500 computer runs had been made using the WES simulation mode1.

In 1976, Daggett and McCarley [23] begin a comprehensive study of traffic through the Winfield Locks on the Kanawha River in West Virginia. This project included a simulation based on the WES TOWGEN-WATSIM IV package. The main purpose of this study was to determine the capacity of the existing system (two $360 \mathrm{ft}$. by $56 \mathrm{ft}$. chambers with a normal lift of $28 \mathrm{feet}$ ) using current policies and to estimate the capacity using several alternative operating policies. In addition, it was planned to determine the effect that several proposed structural changes in the existing waterway (including the replacement of the existing locks) would have on traffic capacity and delay times. Finally, a system-wide analysis was planned for the entire waterway. This study had to be suspended several months later with only a portion of the anticipated work completed in order to reanalyze the proposed replacement of the Gallipolis Lock. Nevertheless, a substantial amount of work was done. The capacity relative to the existing facilities and to several alternative operating policies was determined. The abreviated project provided an indepth test of the TOWGEN-WATSIM IV package at a single lock. Detailed comparisons were made between observed delay times and those predicted by the simulation. Four alternative operating policies were simulated:

- First In-First Out (FIFO) Unrestricted,

- First In-First Out with the assumption of a $10 \%$ reduction in lockage component times,

- FIFO Ready-to-Serve,

- 3 Up-3 Down Unrestricted. 
The ready-to-serve restriction prohibits breaking or remaking of tows sufficiently close to the lock to cause traffic delay. In unrestricted traffic, tows need not adhere to this regulation. The ready-to-serve operating policy would require several switchboats at the lock to facilitate the passage of vessels and and so may not be practical. However, this policy resulted in the most efficient use of the lock chambers. The 3-up, 3-down policy proved to be worse than the FIFO policy because the short entry was not sufficiently shorter than the long entry and so did not compensate for the empty turnaround of the chamber.

The report put out by Daggett and McCarley [23] provides an unusually detailed picture of the way in which a simulation package is used in a particular study. First, data collected by the Performance Monitoring System (PMS) program $11 /$ for July 1975 was obtained to be the primary inputs for the simulation. These consisted of over 300 tow lockages. Also, lockage data for May, September and December were used in formulating average statistics for comparison with the July data and for determining season effects on lockage and traffic characteristics. Before the model could be used, it had to be calibrated. That is, the parameters inherent in the model must be set at levels reflecting the operation of the Winfield Lock. Using the December 1975 data, the following adjustments were made:

- the horsepower vs number of barges per tow frequency distribution was revised to permit the model to more closely reproduce the actual mix of the several types of lockages,

\footnotetext{
11 /The Performance Monitoring System will be discussed in greater detail later in this report.
} 
- dedicated equipment percentages for several of the barge types were adjusted in order to reproduce the correct ratio of empty to loaded barges,

- chamber penalty times for selected lockage types were varied in several runs so that the use of the two chambers by various size tows could be more closely represented.

Explanations are given for the deviations in the case of the Winfield Lock as compared to the general situation incorporated into the WES model. The output of the final calibration run matched the prototype data exceptionally well. For example, the total number of tows passing through the lock during the sampling period was reproduced within $4 \%$ by the model. Using the calibration input data (lockage component times, flotilla makeup, tonnages, etc.) and the July 1975 O-D matrix, the tonnage passing through the lock as obtained by the model was within $1 \%$ of the actual tonnage as obtained from the available data. Other outputs reproduced in this way were unusually accurate. With one exception, all output figures and the July 1975 data were within $10 \%$ of each other. The one exception was the number of barges using the second chamber. The devlation in this case was $12 \%$ and was caused in part by the heavy use of the second chamber by pleasure craft.

After the completion of the calibration, the effect of seasonal variations was investigated using data available from the six year period $1970-1975$. As a result of this investigation it was decided that variations due to the season were negligible and could be ignored.

The input to the TOWGEN program is a listing of commodity flows. These data were available for 1975 and were projected for eight different years in the future out to 2017. Two primary approaches were used to analyze the capacity 
of the existing lock facilities: increases in delay times and increases in lock utilization, both as functions of increased commodity tonnages. Delay times reflect the economic $12 /$ costs to shippers as well as the physical capacity of the lock. For each of the four queueing disciplines described above, the analysis involved plotting the values obtained from the simulation, determining the range of experimental sample values, fitting functions, and plotting curves to these data points. These curves (monthly delay vs monthly tonnage, annual tonnage vs utilization, and annual delay vs utilization) are presented in the report. It was found that, especially during periods of high utilization of the lock, delay time was quite sensitive to changes in the make-up of the traffic assumed for the waterway. Even when assuming constant traffic levels and examining several time periods, it was found that delay times varied greatly. It was believed that a major part of this variation was due to the wide range in the number of cuts required by some tows in order to pass the lock (tows requiring as many as 8 lockages occur at the Winfield Lock) and to the wide range of lockage tines required to service various tows.

The Winfield Lock study, though incomplete, has been discussed here in more detail than other studies for two reasons;

- it is quite recent (appearing in February 1977) and so reflects the state-of-the-art in waterway simulation,

- such step-by-step details as are provided by the authors are found in very few other papers.

\footnotetext{
12 /Since delay time reflects economic costs to shippers, it is a more relevant factor than lock utilization in a multi-modal study where excessive delay using one mode of transportation can bring about a change by the shipper to another mode of transportation.
} 
In falrness, it should be pointed out that the detail presented in a printed research paper is often not determined by the author but, rather, by the editor of the journal in which the paper appears. Since editors of technical journals are universally anxious to save space, few authors are permitted such full exposition as is found in the paper by Daggett and McCarley. For example, neither of the two printed papers $[13,16]$ describing the PSU-COE model contains more than a very small fraction of the detail contained in the six volume PSU report. 


\section{Queueing Theory}

It is generally agreed that queueing theory was founded by A.K. Erlang in a series of papers which appeared during the period $1909-1920$ [35]. The context in which Erlang worked (at the Copenhagen Telephone company) was the problem of determining what number of automatic telephone exchanges was sufficient in order to provide a satisfactory level of service to telephone customers. After 1920 interest in queueing theory grew rapidly and in 1957 Doig [32] published a bibliography devoted solely to queueing theory that contained over 600 items. Since 1957 research in queueing theory continued to expand and, in addition, has diversified steadily so that today it is a widely pursued discipline within applied mathematics. A major impetus for this expansion has been the successful application of queueing theory to widely divergent fields. For example, Pritsker and Young [68] have pointed out that queueing theory has been applied to production lines, job-shop scheduling, all sorts of traffic flows, fire department operations, courts of justice, etc. In addition to the queueing theory studies devoted to solving applied problems, a large body of general abstract queueing theory was developed at about the same time. Abstract queueing theory refers to that portion of research which is not application specific. The first text books devoted to queueing theory appeared in the early 1960's. They made accessible to the mathematical community a powerful tool which could be applied to appropriate problem areas.

Considering the wide variety of application of queueing theory mentioned above, it is not surprising that the same basic queueing problems have been repeatedly attacked with different applications in mind. Usually such research is found in the literature devoted to the area of application and it 
is unlikely to be seen by researchers in a completely different field. Such duplication of effort will undoubtedly continue until a convenient and efficient means can be found to search the entire queueing theory literature for a particular queueing scenario. However, the problem is compounded by the fact that each area of interest maintains its own vocabulary and it becomes difficult to "translate" a paper from the one application area to another.

In general, a queueing problem is specified by describing three basic components :

- the arrival of customers to be served,

- the servicing of these customers by the server(s),

- the servers.

Thus, for example, it is necessary to know not only how many customers are expected in a given time period, but also whether they come singly or in batches, whether they come in a random order or in a preassigned sequence, etc. There are similar questions dealing with the service provided by the servers. Although it is necessary to specify the rule describing the order in which customers are to be served, in the vast majority of queueing theory research it is assumed that service is provided on a first-come, first-served (FIFO) basis. When there is more than one server, it is necessary to know how customers are assigned to each server. Finally, any special features of the particular queueing problem must be described, e.g., are customers likely to give up and leave the queue after a prolonged wait, $13 /$ or, when there is more

$13 /$ Clearly this situation is not applicable to a queue of tows waiting at a lock. However, a shipper faced with long delays in the past may choose another mode of transportation and so "leave" the queue. 
than one server does service of one customer interfere with the service of another customer? ${ }^{14} /$

Although it might be reasonable to consider queues in which the arrival time of each customer and the length of time required to serve each customer are known precisely, such situations are seldom studied since they rarely occur in practice and they provide little fodder for mathematical attack. Typically, both the arrival of the customers and the service time for each customer are assumed to be governed by a probability distribution function. The standard notation in the mathematical literature for a queue in which

- the arrival times of customers are governed by probability distribution $\mathrm{X}$,

- service times are governed by probability distribution $Y$ and

- there are $s$ servers

is $\mathrm{X} / \mathrm{Y} / \mathrm{s}$. The average number of customers that arrive in a fixed time period is called the arrival rate and is usually denoted by $\lambda$. The average number of customers that can be served in the same time period (assuming that customers are always available to service) is called the service rate and is usually denoted by $\mu$. The ratio of $\lambda$ to $\mu$, that is, $\rho=\lambda / \mu$ is called the traffic intensity of the queue and is a critical factor in determining the length of time that a customer will have to wait for service. There is one queueing model which is used as a starting point in every treatment of the subject. Fortunately, this model fits the lock and dam scenario fairly well. In this model it is assumed that customers arrive at random, that is, if time is thought of as being broken up into a large number of "small" non-over-lapping intervals of the same size, then

\footnotetext{
14 /This question is certainly applicable to a queue at a multiple chamber lock.
} 
- It is not possible for two or more arrivals to take place in a single interval,

- the probability of one arrival is the same in all of the small intervals (and is proportional to the length of those intervals),

- the probability of an arrival in any one interval does not depend on whether or not arrivals have occured in any previous interval This is known as Poisson input and its level is given in terms of the mean arrival rate $\lambda$. The probability distribution for the service time is assumed to be of the same type as for arrivals, that is,

- there is no possibility that two or more customers will finish service in the same small interval of time (even if there is more than one server),

- the probability that a customer will finish service in a small interval is the same for all intervals and for all servers (and, for each server is proportional to the length of the interval),

- the probability that a customer finishes service in any one interval does not depend on whether or not customers have finished service in any previous interval.

This is known as exponential service time. The mean service time is given in terms of $\mu$. Finally, the number of servers is denoted by $s$. The simplest case is when there is just one server. This queueing model is denoted by $M / M / 1$. Fuller mathematical discussions of $M / M / 1$ can be found in any standard text book on queueing theory, e.g., [71] or [78]. It is not possible to discuss here the many generalizations and variations of this model which are found in the mathematical literature. Instead we will restrict out attention to those queueing systems that arise in the modeling of locks and dams. 
Thus far, all of the information about a queueing system which has been discussed above is concerned with how the system behaves once it is started. In addition to this ongoing information, in order to completely specify a queueing situation, it is necessary to provide start-up information. That is, a beginning time $(t=0)$ is selected and the description of the system at this time is given. On the basis of the ongoing queueing assumptions and the start-up information, it is possible (at least in theory) to find the probability that the system will be in any given state at any later time. (Of course, the state of the system can only be specified in terms of probabilities since the arrival and service times are provided in probabilistic terms.)

It can be shown mathematically that all (well-behaved) queueing systems settle down to a steady-state condition. That is, although the probabilities for the various states of the system at a time $t$ depend on the value of $t$, unless $t$ is quite small these respective probabilities are nearly the same for all values of $t$. In fact, the larger $t$ is, the less is the variation of the system in terms of $t$. In the long range, the system settles down to a (probabilistically specified) condition from which it does not change. This condition is called the steady-state of the queue, and it is usually much easier to find than the description of the system in terms of $t$. Moreover, as $t$ increases, the effect on the system of the start-up arrangements dies out. Fortunately, for most practical purposes, the steady-state condition of a queueing system provides most of the useful information about its long-term behavior. 
10. Queueing Theory Applied to a Single Chamber Lock

The use of queueing theory to analyze delay and waiting times at a lock appears to have been introduced by Lave and De Salvo in two related papers, both published in $1968[31,56]$. The impetus for these studies was an investigation of the percentage of the active time ${ }^{15}$ of a towboat accounted for by each of 10 categories of delay. Data for these 10 categories of delay were obtained for a sample of 19 towboats during the period 1960-1964 on the Lower Mississippi, Upper Mississippi, Ohio and Illinois Rivers. Total delay amounted to about $25 \%$ of active time. Waiting for and being serviced by a lock was found to be the greatest single cause of delay, accounting for $30 \%$ of total delay time and $7.29 \%$ of active time. In fact, since the Lower Mississippi River contains no locks and, during the high water season on the Ohio River most locks are "collapsed" to permit open river operations, delay caused by waiting for and being served by a lock represented a much higher percentage of total delay time and of active time on a locking waterway.

In order to estimate the expected waiting time in a queue and the expected service time for a lock, Lave and De Salvo assumed that the arrival rate $\lambda$ was Poisson and the service rate $\mu$ was exponentially distributed, that is, they assumed that the operations of a lock could be modeled by an $M / M / 1$ queueing system. In order to test their model, they tabulated the delays experienced by one towboat operating on the Illinois River during the first six months of 1967. This represented about 35 transits of each of the locks being studied. To predict waiting time, it was necessary to obtain the number of tows (represented by $K$ ) for each lock for a period of one year. The arrival rate $\lambda$ (in

\footnotetext{
15 / The active time of a towboat excli les only the periods when it undergoes major repairs or is otherwise unready for service.
} 
tows per hour) for each lock is equ.l to $\mathrm{K}$ dlvided by 8760 . The service rates $\mu$ (in tows per hour) were obtained from a study of these locks for 1949 and 1950. Table 5 presents a comparison of the predicted and observed total walting time in queue $\mathrm{T}_{\mathrm{L}_{\mathrm{q}}}$ (in hours) for each lock.

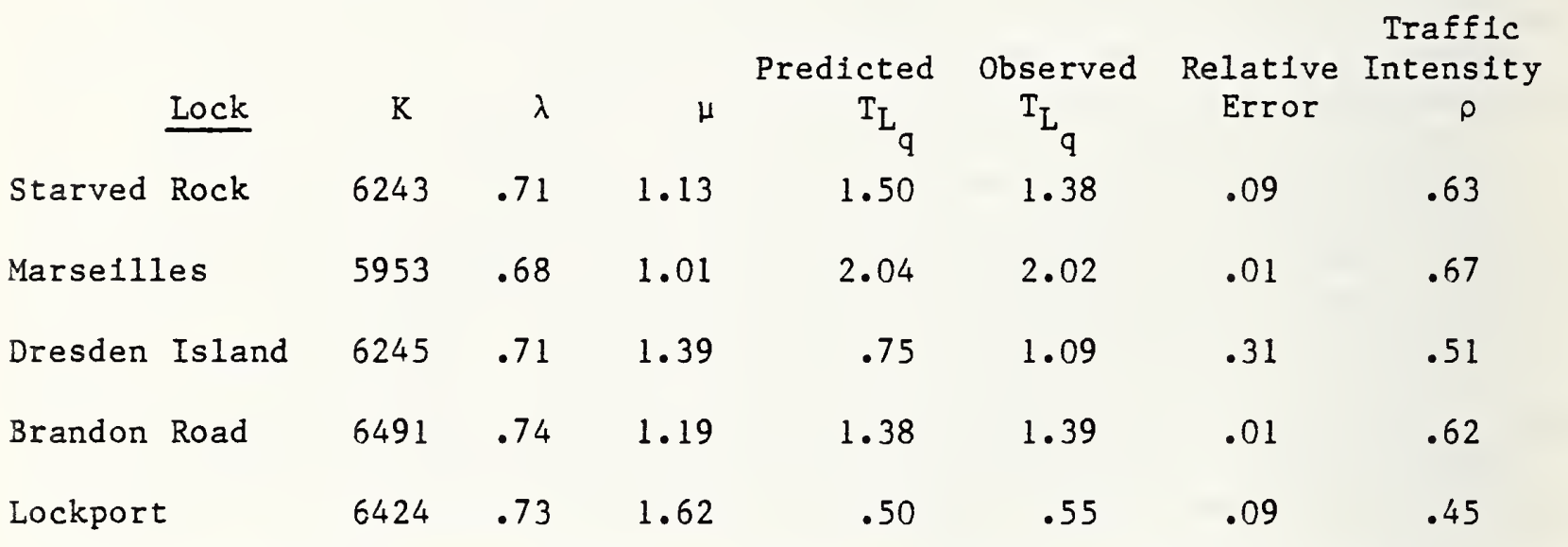

Table 5. Predicted and Observed Total Walting Time in Queue

The predicted $\mathrm{T}_{\mathrm{L}_{\mathrm{q}}}$ is given by the formula

$$
\mathrm{T}_{\mathrm{L}_{\mathrm{q}}}=\frac{\lambda}{\mu(\mu-\lambda)}
$$

The relative error is the difference between the predicted and the observed waiting times divided by the observed waiting time. On the basis of these relative errors, Lave and De Salvo concluded that the $M / M / 1$ model seemed to fit the situation at the locks quite well. No attempt was made to explain the significantly larger relative error at Dresden Island.

Of the 10 categories of towboat delay listed by Lave and De Salvo, 6 are not related to the waterway itself (e.g., waiting for supplies, cargo or crew, making minor repairs, etc.). Of the 4 categories related to the waterway, 2 account for significant percentages of active time $16 /$. The first of these, locking, has already been discussed. The second is delay caused by the making

16 /The remaining two categories, delay at bridges spanning the waterway, and running aground account for $.12 \%$ and $.24 \%$ of active time respectively. 
and breaking of tows, that is, by the assembly of the tow at the beginning of a trip and the disassembly at the end. Also included are the times needed to pick up and drop off barges during an intermediate stop. Making and breaking tows consumes approximately $3.16 \%$ of towboat delay. Although the time required for either making or breaking a tow reflects the availability of auxiliary equipment (e.g., a switchboat waiting at docks to handle dropped barges), it has been observed that a major influence on the delay was the number of barges involved. However, the specific relation between the delay time and the number of barges was not known. Lave and De Salvo set up and tested linear regression models for the time spent in making a tow, $\mathrm{T}_{\mathrm{m}}$, and for the time spent in breaking a tow, $T_{b}$, in terms of the number $N$ of barges added or dropped

$$
\begin{aligned}
& T_{m}=a+b N, \\
& T_{b}=c+d N .
\end{aligned}
$$

They also set up and tested log-linear models

$$
\begin{aligned}
& \log T_{m}=a+b \log N \\
& \log T_{b}=c+d \log N .
\end{aligned}
$$

Data were collected from the log books of two towboats. There were 242 observations on the time required to make a tow and 247 observations on the time required to break a tow. On average, 1.7 hours were needed to make a tow and 1 hour was needed to break a tow. The number of barges added ranged from 1 to 24 with an average of 3.4. The number of barges dropped ranged from 1 to 16 and averaged 3.1. It was found that the Iinear regression model provided a better fit to the data than did the log-linear model both for making and breaking a tow. For the linear regression model, $78 \%$ of the variation in time taken to make a tow and $63 \%$ of the variation in time taken to break a tow is accounted for. The corresponding figures for the log-linear regression model 
are $66 \%$ and $49 \%$ respectively. Moreover, the significance levels of the coefficients in the linear regression model are all below .06. Lave and De Salvo conclude that the statistical results for the linear regression model are quite good.

In 1972, Hayward [44] Investigated the assumptions which underlay Lave and De Salvo's decision to use the classical queueing model $M / M / 1$ to study the operation of a single chamber lock. For his study, Hayward selected the Plckwick Lock on the Tennessee River. The Pickwick Lock is a single chamber lock that is in many ways typical of locks on the inland waterways system. The chamber Is 600 feet long by 110 feet wide - a quite common s1ze. Moreover, Carro11 [10] had previously performed an analysis of the operations of the Pickwick Lock while developing the original TOWGEN-LOKSIM simulation package and so considerable simulation data already existed for comparison with data obtained from various queueing models. Nowhere does Hayward use real-world data.

In 1968, Carroll [10] determined that arrivals at the Pickwick Lock were random in nature and so fitted the assumption of Poisson arrivals. In 1972, Desal [30] confirmed Carroll's finding and showed that arrivals at most of the locks on the Illinois and Ohio Rivers systems could be considered random. Therefore, in all the models considered by Hayward, he assumed that arrivals were random. He compared the outputs of 5 models (Lave and De Salvo's queueing theory model and 4 computer simulations) for traffic passing through the Pickwick Lock. The 5 models Hayward considered were

- the classical $\mathrm{M} / \mathrm{M} / \mathrm{l}$ queueing theory model of Lave and De Salvo,

- Carroll's computer simulation (the ancestor of LOKSIM) which used SOQA queue discipline and service time expressed as the sum of entry time, lock ng time, exit time and recycling time, 
- LOKSIM simulation modeling the $M / M / 1$ queue as closely as possible using a FIFO queue discipline,

- LOKSIM simulation modeling the $M / M / 1$ queue but using SOQA queue disc1pline,

- LOKSIM simulation with SOQA queue discipline and the same type of service time as in Carroll's 1968 model.

In each case, it was assumed that traffic consisted of $70 \%$ single lockages and $30 \%$ double lockages with an average service time of 82.7 minutes per tow. These figures were considered typical by Carroll and were used in his 1968 study. For each of the 5 models described above, a graph was constructed to show how average delay time depends on the arrival rate. For the queueing theory model, the formula for delay time obtained by mathematical analysis was graphed. For each of the 4 computer simulation models, 4 to 6 different arrival rates were selected as input. For each arrival rate and for each model, a simulation was run unt11 1000 tows had been passed through the $10 \mathrm{ck}$. The average delay time per tow was obtained as the output of these simulations yielding a single data point per tow (arrival rate, average delay time). The data points were connected to form a graph.

The average service time of 82.7 minutes per tow assumed by Hayward is equivalent to a service rate of $\mu=.73$ tows per hour. The arrival rate, $\lambda$, was varied from .03 to .58 tows per hour ylelding corresponding traffic intensities, $\rho$, varying from .11 to .79. Although all five curves drawn by Hayward have the same general shape, they fell into two distinct groupings. The queueing theory and simulated queueing theory curves consistently predicted longer average delay times than did the other 3 models. The models based on queueing theory and simulated queueing theory were the only ones that used the 
FIFO queue discipline. It is difficult to determine from Hayward's work whether the longer average delay times predicted by these models were due to

- queueing theory vs lockage simulation

- FIFO vS SOQA

- chance

- none of the above.

However, Hayward ascribed the longer predicted delay times to the queue disciplines.

Predicted average delay times did not appear to be influenced by the choice between Poisson service times and service times based on the various components of a lockage. When $\rho$ reached .75 , Lave and De Salvo's model, as applied to the Pickwick Lock, predicted an average delay per tow more than 100 minutes longer than the average tow delay predicted by the LOKSIM simulations of traffic through a lock. Since information about delay time is needed mostly for larger values of the traffic intensity, Hayward claimed that Lave and De Salvo's model performed inadequately. It should be noted that in Lave and De Salvo's study, traffic intensity, $\rho$, ranged only from .45 to .67 .

In 1977 Wilson [82] continued Hayward's analysis of the adequacy of Lave and De Salvo's M/M/I queueing model for a single chamber lock. Wilson noted that, according to Carroll's observations at the Pickwick Lock, the empty chamber cycle time was approximately equal to the difference between the times for a long and a short entry. Thus, in the case of the Pickwick Lock, the choice of queueing disciplines, (FIFO vs SOQA) should not affect the average delay time per tow although it might have a considerable effect on the delay time of a 
specific vessel $17 /$. Wilson pointed out that exponential service times are unrealistic since the cycle time was approximately 15 minutes and so complete service times of shorter duration are not possible. For this reason, he reverted to Carroll's service time which consisted of the sum of entry time, lockage time, exit time and recycling time $18 /$. The model with Poisson arrivals Carroll's service times, one server and unspecified queue discipline was referred to by Wilson as $M / G / 1$. The assumption of a $70 \%$ single lockage and a $30 \%$ double lockage mix used by Carroll and Hayward was retained by Wilson. The average lockage times for single and double lockages were taken as 59.1 and 133.0 minutes respectively. These result in an average lockage time of 81.27 minutes (Hayward had used 82.7 minutes). In addition to the average lockage times, Wilson also made use of the variances of the lockage times. His formula for the average delay time (given without derivation or reference) was $19 /$

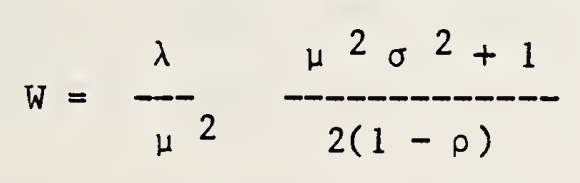

where $\sigma^{2}$ is the variance of the lockage time. Using Carroll's version of service time, the variance of the lockage time is 1347.7. Using exponential service times, the variance of the lockage time is 6604.8 . Both of these figures are based on an average locking time of 81.27 minutes. According to Wilson, it is the large difference in the variances which was responsible for the consistently higher expected average delay times obtained using Lave and

\footnotetext{
17 / Note that Hayward came to the opposite conclusion, claiming that the difference between the two queueing disciplines, FIFO and SOQA, was the major cause of the failure of Lave and De Salvo's model.

18/ According to Hayward, changing from exponential service times to Carroll's service times did not affect the average delay time per tow.

19/ This formula differs from the one given by Hillier and Lieberman [46] and used by Rao [69].
} 
De Salvo's $M / M / 1$ model than were obtained from either the $M / G / 1$ model or from computer simulations of lockages. (See Table 6.) Wilson expressed surprise that Lave and De Salvo's relative errors were as small as they were considering both the much greater variance of lockage time in their model and the relatively poor results obtained by him on the Pickwick Lock using their M/M/1 mode1.

\begin{tabular}{ccccccc}
\hline $\begin{array}{l}\text { Arrival Rate } \\
\text { (tows/day) }\end{array}$ & $\rho$ & $\begin{array}{c}\text { Mean Delay } \\
\text { (minutes) } \\
\text { simulated }\end{array}$ & $\begin{array}{c}\text { Mean Delay } \\
\text { (minutes) } \\
\text { M/G/1 }\end{array}$ & $\begin{array}{c}\text { relative } \\
\text { error }\end{array}$ & $\begin{array}{c}\text { Mean Delay } \\
\text { (minutes) } \\
\text { M/M/1 }\end{array}$ & $\begin{array}{c}\text { relative } \\
\text { error }\end{array}$ \\
\hline 2 & .11 & 6.4 & 6.2 & .03 & 10.3 & .66 \\
4 & .23 & 13.7 & 14.3 & .04 & 23.7 & .66 \\
6 & .34 & 24.8 & 25.1 & .01 & 41.6 & .66 \\
8 & .45 & 40.0 & 40.3 & .01 & 66.9 & .66 \\
10 & .56 & 66.0 & 63.4 & .04 & 105.3 & .66 \\
12 & .68 & 111.5 & 102.7 & .09 & 170.5 & .66 \\
14 & .79 & 209.7 & 184.2 & .14 & 306.0 & .66 \\
16 & .90 & 477.4 & 455.5 & .05 & 756.6 & .66 \\
\hline
\end{tabular}

Table 6. Comparison of Carroll's Simulation results with Wilson's M/G/1 results and results using Lave and De Salvo's M/M/1 model.

In 1976, CACI, Inc. [20] prepared a study on waterway and rail capacity for the Department of Transportation. An integral part of this study was the Lock Capacity Function Generator ( $L C F G$ ), a model of traffic on a waterway using mathematical queueing theory. The LCFG assumed Poisson arrivals, a general probability distribution with known mean and variance for service times and one server. Thus the CACI model, like Wilson's, is in the M/G/I category. Service time was expressed as the sum of approach time, entry time, chamber time and exit time, together with a provision for recycling time when needed. 
Unliked the other queueing models, up-stream and down-stream traffic were treated separately. Input data on lockage times, barge loadings and tow size distributions were obtained from the Performance Monitoring System (PMS) of the COE. The output of LCFG was compared with the output of the Inland Navigational System Model which is a part of the INSA program. The LCFG output was also compared with real-world data supplied by PMS. When average locking times predicted by the LCFG model were compared with data obtained from PMS, relative errors ranged from .01 to .54 .

The LCFG model was used to study 9 portions of the Mississippi River/Gulf Intracoastal Waterway System. The CACI study Investigated locks of varlous sizes (from $360 \times 56$ to $1200 \times 110$ ) on several rivers of the Mississippi River system as well as two locks on the Gulf Intracoastal Waterway system. Among the outputs of the model were estimates of the delay time of a tow and the expected average queue length. The formula for the average delay time was the same as the one used by Wilson (equation 6 ).

The studies by Lave and De Salvo, Hayward, Wilson and CACI, Inc. described above appear to represent the totality of research on the application of queueing theory to a single chamber lock performed in the United States. Furthermore it appears that the application of queueing theory to traffic through a lock has not been treated in the foreign literature. There are several other studies performed in the United States devoted to multiple chamber locks and these will be discussed in the next section. However, aspects of the problems associated with multiple chamber locks of ten raise questions about the analysis of a single chamber lock. For example, although Glassey and Ross [40] were concerned exclusively with parallel chamber locks, their questioning of the prevailing assumption of Poisson arrivals at a lock 
opens the door to reinvestigating this point for single chamber locks. The question of Polsson arrivals was also studied by Desai [30] who concluded that arrivals followed a Poisson pattern in 67 of 80 queues at 40 locks. Glassey and Ross were concerned primarily with Lock and Dam No. 26 on the Upper Mississippi River and their data are drawn from the traffic there. According to their observations, waterway traffic is not homogeneous but is

- highly seasonal,

- heavier during daylight hous than at night,

- lighter on weekends than during the week.

The seasonal variation in traffic intensity is considerably greater than the day/night variation. How significant these factors are is not studied in deta1l, but nevertheless bring into question the assumption of Poisson arrivals. In fact, the average waiting time per tow as calculated with the assumption of Poisson arrivals is shown to be a lower bound for the true average waiting time. Whether this lower bound is significantly lower than the true average waiting time has not yet been determined.

In 1979, Rochberg [72] looked at the various methods that had been used to analyze the capacity of a lock, the average waiting time of a tow, etc. and presented a critique of each. In only a limited way did he present any alternative suggestions for modeling which he felt would be an improvement over existing methods. Rather he was concerned with reevaluating the models put forward by other authors. For examples Rochberg pointed out that while average delay time per tow remains the standard variable to be solved for in both queueing theory models and by computer simulations, other related variables (e.g., average delay time per barge, per ton of cargo, or even, per ton of a specific cargo) might be more relevant. In addition, a situation which achieves a low average delay time per tow by having a few tows wait an 
inordinately long time while the majority of tows have virtually no waiting time (say a 12-up, 12-down queue discipline) would not be acceptable. Thus, minimizing the maximum expected waiting time that a tow might be faced with could be a better criterion for satisfactory locking facilities than minimizing the average waiting time per tow.

It was pointed out by Rochberg that many real-world variables can not be satisfactorily introduced into a theoretical treatment (e.g., horsepower of towboats, weather conditions, etc.) and that no attempt had thus far been made to estimate the importance of such variables in obtaining meaningful results. In order to use queueing theory properly, the validity of the assumptions and inputs must be carefully evaluated. In general these are usually roughly correct but seldom completely accurate. Rochberg demonstrated just how sensitive the results obtained in queueing theory can be to parameters which either do not remain constant or are difficult to measure with precision (e.g., traffic intensity, locking time, etc.). For example, using an $M / M / 1$ queueing model with an average service time of one hour and tows arriving at an average of every 61 minutes, there would be, in the long run, a sixty hour wait. However, if tows arrive at an average of one very 70 minutes then the average wait in the long run would be only 6 hours. If we change the assumptions and assume that the service time is exactly one hour $20 /$ (rather than an average of one hour) then the average waiting time is cut to 3 hours.

According to Rochberg, the average waiting time per tow is given by

$$
w=\frac{c \lambda \mu}{\mu-\lambda}
$$

20 /For example, this phenomenon occurs when traffic passes through several locks in a short span of waterway. 
where $c$ is a quantity to be specified and depends on whether arrival and service times are random or not. When the quantity $\mu-\lambda$ is small, $w$ is extremely sensitive to even small changes in $\lambda$ and $\mu$.

Although the queueing models $M / M / 1$ and $M / G / 1$ are capable of being solved mathematically, changing the queueing model to reflect more accurately the operations of a lock usually results in a mathematical system which is untractable by currently-available techniques. There are schemes for approximating the solutions of such a queueing system by numerical methods. However, these methods themselves introduce an error of their own.

The problems involved in producing information about the operation of a waterway by means of a computer simulation are quite different from those which arise when queueing theory is used. Much more detailed data is needed as input for a computer simulation model. For example, queueing theory requires the average time for a lockage and, perhaps, the variance of the lockage time. A computer simulation uses a spectrum of lockage times as well as the probability distribution for the various lockage times. One of Rochberg's main criticisms of the way in which computer simulations are used is that the lengths of computer runs are usually arbitrarily chosen (except that they must be "long"). Of course, "long" is a very vague term. Rochberg pointed out that even a computer run which is generally considered to be sufficiently long might nevertheless not be long enough to show that a queue at a lock would grow indefinitely or would reach unacceptable length, not immediately, but in the foreseeable future.

With the current state of the art, simulations seem to provide more accurate results than does queueing theory, even though, because of the randomness introduced into a computer simulation, results cannot be exactly duplicated. 
However, Rochberg suggested that simulations can be improved by making use of information that a queueing theory analysis can provide. For example, queueing theory is often able to evaluate the variance of delay time (or of other variables involved in a simulation). This information can be used to determine how long a computer simulation run should be in order to provide a specified confidence level for the output. For example, when the variance of a variable is known, it is not difficult to determine how long a computer run is necessary in order to have, say $95 \%$ confidence that the computed value of the variable differs from the variable with a relative error of at most .01 . The variance of a variable such as delay time can be estimated by using a large number of computer simulation runs but such a procedure is time consuming, expensive and probably produces less accurate results than those obtained using queueing theory methods. 
11. Queueing Theory Applied to Multiple Chamber Locks

For locks with two or more chambers, there are a number of factors which can add serious complications to the comparatively simple model of a single chamber lock. For example, when there are two chambers at a lock, separated as much as possible by having one adjacent to each bank of the river, then the interference of traffic through one chamber with traffic through the other is obviously less than when the two chambers are adjacent to each other. If the assumptions of independence for the arrivals, operations, service times, exits, etc. at the two chambers can be justified (e.g. by observations at the lock) then the mathematical analysis of the lock using queueing theory is substantially simplified. Another simplifying assumption (whether or not traffic at one chamber behaves independently of traffic at the other chamber) is that the two chambers are identical - at least from a mathematical point of view.

A major impetus for the study of multiple chamber locks is Lock and Dam No. 26 which is located on the Mississippi River at Alton, Illinois (north of St. Louis) below the confluence of the Illinois and Upper Mississippi Rivers, The lock contains two chambers - a main chamber 600 feet in length and an auxiliary chamber which is 360 feet in length. Both chambers are 110 feet wide. Barge traffic on the Upper Mississippi and Illinois Rivers increased rapidly after World War II and Lock 26 became a serious bottleneck. Numerous studies were commissioned to determine whether Lock 26 should be expanded, replaced, or left alone. An integral part of several of these studies was an evaluation of the effect on average delay time of the size of a second chamber at the lock. Several researchers were concerned with comparing traffic through one chamber with traffic through two parallel chambers of the same size, although studies which received impetus from Lock and Dam No. 26 considered two unequal parallel chambers. 
Lave and De Salvo [56] considered the benefits that would result from adding a second chamber to a single chamber lock. In the case they studied, the added chamber was to be twice the size of the existing one and they computed the average delay time per tow by assuming that the avallability of a parallel chamber would cut the average service time per tow in half. The average delay time per tow was then calculated by treating the double chamber lock as a single chamber lock with the reduced average service time per tow. Hayward [44] disputed Lave and De Salvo's claim that the average service time per tow would be cut in half. He presented his own formula for the average service time but provided neither a reference nor a derivation.

In 1976, Glassey and Ross [40] compared observed average waiting time per tow for the two chambers of Lock and Dam No. 26 with calculated average waiting time using the $M / G / 1$ model coupled with the assumptions of independent chambers, Poisson arrivals and independent service times.

$$
\begin{array}{cccccc}
\lambda & E[S] & E\left[S^{2}\right] & \begin{array}{c}
W_{Q} \\
\text { (hours) }
\end{array} & \begin{array}{c}
W_{0} \\
\text { (hours) }
\end{array} & \begin{array}{c}
\text { relative } \\
\% \text { error }
\end{array}
\end{array}
$$

$\begin{array}{llllllll}600^{\circ} \text { chamber } & .646 & 1,466 & 2.753 & 16.79 & 6.53 & 157 & .947 \\ 360^{\circ} \text { chamber } & .4865 & .8523 & 1.320 & .549 & .814 & 32.5 & .415\end{array}$

Table 7. Comparison of Observed and Calculated Average Waiting Times for Each Chamber at Lock and Dam No. 26

$E[S]$ is the average service time, $E\left[S^{2}\right]$ is the average of the square of the service time, $W_{Q}$ is the calculated average waiting time and $W_{O}$ is the observer average waiting time. The observed data were taken from the lock operating $\log$ for a 26 week period beginning March 1, 1974 and represent a total of 5171 observations. 
Glassey and Ross suggested that the poor performance of the $M / G / 1$ model in predicting the average waiting times at both chambers was due to the inaccuracy of the assumption of homogeneous random arrivals. However, they concluded, this cannot be both the cause of the estimate for the average waiting time at the large chamber to be too large and the cause of the estimate at the small chamber to be too small. Thus, another explanation was needed to explain the poor performance of the $M / G / 1$ model. To this end, they argued that, since average waiting time at the small chamber was considerably less than at the large chamber, more tow captains chose the small chamber than would have been expected to under the assumption of independent chambers. In order to incorporate this idea into the model, they presented a modification of the $M / G / 1$ model by assuming that there was a number $N$ such that at any time when the queue at the larger chamber reached a length of $N$, then all traffic would be diverted to the smaller chamber $21 /$. In order to select an appropriate value for $\mathrm{N}$ it was assumed that whenever the small chamber was found to be empty by an approaching tow, then the tow would use the small chamber instead of the large one. Thus, $N$ was obtained in terms of the proportion of time that the queue could be expected to be empty using the $M / G / 1$ model. The average waiting time at each chamber as calculated with the model incorporating this modification was considerably closer to the observed average waiting time than had been obtained from the model prior to the modification.

Glassey and Ross argued that tows containing a sufficiently small number of barges would have less reason for preferring the large chamber than would tows

\footnotetext{
21 The possibility of queues of length $\mathrm{N}$ at both chambers or at the smaller chamber alone was not discussed.
} 
with a large number of barges since some tows which could pass through the large chamber in a single lockage would require a double lockage when using the small chamber. As a means of avolding the difficulty involved in making a specific assignment of tows to chambers, they developed a model in which barges form a single queue which feeds both chambers. The barges were assumed to arrive in batches of random size. In this model the lock is a two server system. However, since queueing systems of the form M/G/2 are mathematically complicated when service rates are unequal, Glassey and Ross developed an "equivalent" single server system (M/G/I) having approximately the same service characteristics. Such a model yielded the average waiting time per barge, rather than the average walting time per tow. Although detailed numerical calculations were not carried through, Glassey and Ross pointed out that changing customers from tows to barges did not change the data requirements of the model. In either case, these were

- the tow size distribution,

- the service time distribution (depending on tow size),

- the arrival rate distribution for each tow size.

On important point not made by Glassey and Ross is that when $\rho$ is so large $(\rho=.947$ for the large chamber) the average waiting time is extremely sensitive to the data. For example, if we change the values of $\rho$ and $E[S]$ for the large chamber from .646 and 1.466 to .6 and 1.4 respectively then $w_{Q}$ is changed from 16.79 to 5.16

In 1977, Rao [69] presented a comprehensive study of the many aspects of evaluating navigation investments with the intention of optimizing the returns from expenditures whose aim is to reduce congestion. This study was the author's dissertation for the $\mathrm{Ph}$. D. degree in Business Adiministration at 
Pennsylvania State University, and is considerably broader and deeper than any of the previously-mentioned papers. Rao took the Corps of Engineers' proposal for the replacement of Lock and Dam No. 26 as the impetus for his work. Although the data presented throughout the study refers only to Lock and Dam No. 26, the discussion is consistently presented in terms of the general problem of evaluating navigation investments. The study is comprehensive and includes the political and environmental aspects of waterway navigation and construction as well as discussion of various cost/benefit analyses, alternate modes of freight transportation, appropriate times for investment, etc.

The problem of estimating the capacity of a lock was treated by Rao in detail as an integral part of navigation investment analysis. Tow traffic was divided into classes according to the type of lockage required. For each lockage type, service time was expressed as the sum of entry time, chamber time and exit time. The average service time per tow is the weighted average of the service times for the various types of lockages required. It then became a straight forward operation to calculate the maximum number of lockages which can be performed at the lock in one year. Provisions are included for the average down-time of the lock and for portions of the year when the lock cannot be used because of weather conditions. The maximum number of lockages per year is one measure of capacity investigated by Rao. Another measure of the capacity of a lock is the total tonnage which can pass through the lock in one year. This is equal to the product of the average tonnage per lockage and the number of lockages. The average tonnage per lockage was expressed in terms of the number of barges of each type and the loading of each barge. Other measures of capacity stuided by Rao were

- average tonnage per tow,

- average number of barges per tow, 
- average number of loaded barges per tow.

These were examined in order to determine whether the yearly through-put measures of capacity he obtained reflected prevailing traffic characteristics or represented an idealized situation in which lock capacity can theoretically attain some maximum level. For each measure of capacity, actual 1972 data for each chamber of Lock and Dam No. 26 were obtained and compared with the capacity as calculated using the model. The capacity of a lock was not Rao's major concern. On the contrary, it was studied only because it was needed in the calculation of cost/benefits, in finding the appropriate time for navigation investments and in determining the modal demand for waterway transportation.

Unlike capacity which was an integral part of Rao's study, average delay time was relegated to an appendix. He discussed the classical general $\mathrm{X} / \mathrm{Y} / \mathrm{m}$ queueing model and then applied it separately to each of the I classes of lockage requirements, calling the resulting model $\mathrm{X} / \mathrm{Y} / \mathrm{m} / \mathrm{I}$. The simplest example of such a model is $M / M / 1 / I$ consisting of $I$ classes of lockage requirements, Poisson arrivals for each class with an arrival rate of $\lambda_{i}$ for the $i$ th class, exponential service times for each class with a service rate of $\mu_{i}$ for the $i$ th class, and one server. (This model had been treated by Ross but not in the context of navigation.) Rao then expanded the model to incorporate bidirectional traffic. In both cases, algebraic relations were given from which the average delay time per tow can be found. Unfortunately, the algebra quickly became extremely complex and numerical solutions for a given input data required extensive calculations. For specific numerical values of the arrival rates, service rates and maximum queue lengths, the average waiting time per tow can be calculated but this requires the use of a large scale computer. 
Rao next presented a more sophisticated queueing model, $M / E_{k} / 1 / I$. Again the I classes of customers (possibly tows or barges) referred to the types of lockages required. The service time distribution for the $i^{\text {th }}$ tow class is assumed to be $k_{1}$-Erlang. The $k-E r l a n g$ distribution is the distribution of the sum of $k$ independent exponential random variables. Thus a tow of the $1^{\text {th }}$ class is conceived of as requiring $k_{1}$ distinct steps of a lockage. Each of the steps is presumed to have an exponential distribtuion. This model was solved by the "method of stages" as given by Kleinrock [49] and was illustrated by Rao for a specific simple case.

The average delay time per tow was computed for traffic at 7 locks on the Illinois Waterway and at Lock and Dam No. 25 using the four models introduced by Rao as well as the standard $M / G / 1$ and $M / E_{k} / 1$ models. The output of these six models were compared with the results of the simulation model developed by Carroll and Bronzini in 1971.

Bidirectional

Lock Name Simulation $M / M / 1 \quad M / M / 1 / 3 \quad M / M / 1 / 3 \quad M / G / 1 \quad M / E_{6} / 1 \quad M / E_{k_{i}} / 1 / 3$

$\begin{array}{lrrrrrrl}\text { Lockport } & 62 & 74 & 87 & 87 & 40 & 43 & 52 \\ \text { Brandon Road } & 111 & 111 & 135 & 139 & 83 & 64 & 76 \\ \text { Dresden Island } & 21 & 45 & 53 & 53 & 26 & 26 & 29 \\ \text { Marseilles } & 29 & 52 & 61 & 62 & 29 & 30 & 33 \\ \text { Starved Rock } & 37 & 46 & 56 & 55 & 26 & 27 & 31 \\ \text { Peoria } & 38 & 58 & 66 & 67 & 40 & 34 & 35 \\ \text { LaCrange } & 38 & 49 & 54 & 55 & 28 & 28 & 29 \\ \text { Lock \& Dam No. 25 } & 25 & 30 & 33 & 34 & 19 & 17 & 18\end{array}$

Table 8. Average Delays per Tow with Alternative Oueueing Models (in minutes) 
The values for $k_{i}$ in the last column were 2, 14 and 23 for single, setover and double lockages respectively. At the Lockport and Brandon Road Locks, traffic intensity ranged from 50 to 60 percent. At all other locks the traffic intensity ranged from 30 to 40 percent. Moreover, all locks were single chamber locks.

Several findings can be observed from Table 8. All models which assumed exponential service distributions performed poorly when compared to the simulation results. This agrees with Wilson's findings several years earlier and was the reason he switched from the $M / M / 1$ mode to the $M / G / 1$ model. Also, the assumption of bidirectional traffic (and SOQA queue discipline) has little effect on the output of the model. Further, dividing traffic into three classes according to the type of lockage required resulted in poorer output when the $M / M / 1$ model was used and gave mixed results when the Erlang distribution was used. Unlike several other authors, Rao is satisfied with the assumption of Poisson arrivals.

There were 3 locks (with a total of 4 chambers) for which actual data were available, providing the possibility of making performance comparisons of the various queueing models. The lock with two chambers was Lock and Dam No. 26. Rao chose to compare the available data only with the $M / M / 1$ and $M / G / 1$ models. 


$\begin{array}{lcccc}\text { Lock Name } & \begin{array}{c}\text { Traffic } \\ \text { Intensity }\end{array} & \begin{array}{c}\text { Average Delay } \\ \text { Actual }\end{array} & \begin{array}{c}\text { per Tow (in minutes) } \\ \text { M/M/1 }\end{array} & \begin{array}{c}\text { M/G/1 } \\ \text { Brandon Road }\end{array} \\ \begin{array}{l}\text { Meldahl } \\ \text { Lock and Dam No. 26 } \\ \text { Main Chamber }\end{array} & .91 & 117 & 194 & 6 \\ \begin{array}{l}\text { Lock and Dam No. 26 } \\ \text { Small Chamber }\end{array} & .49 & 319 & 620 & 363 \\ \end{array}$

Table 9. Actual data compared with $M / M / 1$ and $M / G / 1$

The actual data for the two chambers of Lock and Dam No. 26 were collected by the Corps of Engineers in 1975 and Showed substantial agreement with the data used by Wilson. (See Table 7.)

Rao was well aware that his treatment of the traffic at a two chamber lock was in terms of single server models. He stated

The reader may wonder why multiple server models have not been mentioned for use in modeling congestion at multiple chamber locks. There are three main difficulties with the use of multiple server queueing theory. First, where multiple chambers now exist at lock sites on the inland waterways, they are generally of unequal size and have dissimilar characteristics.... Treating multiple servers of unequal size and characteristics via queueing theory becomes rapidly intractable. [Also] at many multiple chamber locks the smaller or auxiliary chamber is not used very frequently, its main purpose being to stand by as a chamber to be used when the main chamber is being repaired or when traffic is extremely heavy. Even in heavy traffic, tow operators generally prefer to use the larger chamber for reasons of safety and ease of maneuverability. Where additional locks have been proposed at existing sites, the design sometimes calls for the new chamber to be separated from the existing chamber rather than adjacently located.... This type of situation can also be appropriately handled by treating the site as consisting of two separate facilities rather than a single multiple server facility. 
12. Queueing Theory in the Foreign Literature

The first phase of this study consisted of locating research dealing with the problem of analyzing traffic on a waterway which had been performed anywhere in the world. To this end, the On-Line Bibliographic Retrieval System, available through the library at the National Bureau of Standards, was used. Three data bases accessible through this retrieval system were selected for search:

- the Engineering Index,

- the Science Citation Index,

- the National Technological Information Service Index (NTIS).

The NTIS Index is concerned primarily with domestic research but also contains a number of translations of foreign language papers and reports on research which was performed abroad but was supported by the United States Government. The Engineering Index and the Science Citation Index are very broadly based and contain references to virtually all of the world's technical journals.

In order to use the retrieval system, a list of pertinent keywords was drawn up to be used as input. These were: lock, queue, channel, traffic, delay, watting, tow, barge and simulation. When any pair of these words were fed into the retrieval system a listing of all papers contained in the Engineering Index whose titles or keywords contained that pair was produced. This listing was supplemented by a number of central papers on lock traffic which had been supplied by the Army Corps of Engineers. Using the Science Citation Index, the retrieval system was then asked to find

- all other papers by the authors of the papers in the listing,

- all papers by any author which used any of the papers in the listing as a reference. 
Finally, as every new paper was found, its reference list was examined in the hope of finding additional relevant papers. In this way, a huge list of potentially relevant papers was obtained. It was then necessary to examine these papers individually in order to determine which of them would contribute to this study. Although the possibility remains that there are important papers in the literature which still have not been found, both the thoroughness of the indices and of the search procedures makes this unlikely. On the other hand, some unpublished papers (such as [44] which was presented as a classroom exercise and was never published or submitted to a government agency) are virtually unknown to the scientific community and are not easily found. Another class of papers which would proved difficult to discover are unpublished reports submitted by private consulting firms (either domestic or foreign) to foreign governments. At present no evidence of the existence of any such papers has been found.

One thing that was immediately apparent when examining the output listings of these searches was the large preponderance of domestic research. Papers from outside the United States accounted for a small fraction (estimated at less than $15 \%$ ) of the total. Whereas simulation models for analyzing traffic on a waterway have been constructed and used in many parts of the world (See Section 7 of this report.) there appear to have been very few attempts outside the United States to apply queueing theory to the problem. Moreover, the level of sophistication in these foreign papers is considerably below that found in the domestic literature. Koehler $[51,52]$ and Leutzbach and Lenz [58], writing in German, examined both vessel flow and cargo flow through a lock of a waterway using queueing theory. However, neither of these treatments consider such aspects of the lock-queueing problem as nultiple chambers, different queue disciplines, multiple lockages, etc. 
As several other authors have done, Koehler questioned the usual assumption of Poisson arrivals. Other authors have tended generally to accept this assumption on the basis of a comparison of the available data and the functional form of the Poisson distribution. Koehler used a standard statistical test, called a goodness-of-fit test, which is based on the $\chi^{2}$ (read: chi-square) distribution, to determine whether arrivals are random. Desai [30] used the same approach to the same problem.

It is interesting to note that a substantial portion of the items on the list of references in the German language papers (including the major reference to mathematical queueing theory) were written in English and published in the United States. On the other had, foreign language references of any kind in domestic papers are virtually non-existent and, when they are found, are usually included for completeness. 


\section{Input and Performance Data}

There is an enormous amount of data continually being published in the United States dealing with all aspects of the cargoes moved in commercial waterborne traffic and of the vessels which carry them. For example, every year the American Waterways Operators, Inc. prepares a report [2] containing extensive listings of the commodities carried along each of the nation's waterways. These listings give the tonnage carried (broken down into ocean-going and inland portions) for each type of commodity on each waterway. In addition, data are provided about the types and sizes of barges used, the number and horsepower of towboats, etc. The prime source of data concerning commercial waterborne traffic is the United States Government which periodically makes available a vast array of statistics. There include detailed information about the orfgin and destination of traffic, seasonal variations in flow intensities, dollar-value of cargoes, net tonnage, ton-miles, etc.

In spite of the large quantity of data being published concerning all aspects of traffic on a waterway, the specific data needs of some researchers may not be met. However, in reading the overwhelming majority of literature dealing with traffic through a lock, it is Impossible to ascertain just what data the author would have liked to have had, what data he actually had avallable to him, and what portion of that he actually used. For example, it has not been uncommon for an author to describe in great detail exactly how he obtained, either by a computer simulation or by a mathematical study using queueing theory, a distribution of arrival times or waiting times of tows at the particular lock in which he is interested. He might then conclude that his model is satisfactory on the basis of comparisons he has made of his results with the available data - without presenting those data or even giving the reader any indication as to the exact data that he used and how he obtained them. 
Even in those papers where the data are presented for comparison, there may be no source provided and so it remains impossible for the reader to verify the author's work.

This off-hand treatment of data often manifests itself in another way. It is quite rare for an author to complain about, or even comment about, the lack of data available to him. When Hayward [43] modeled the Pickwick Lock using a queueing theory model, he compared the results he obtained with the output of a TOWGEN-LOKSIM computer simulation rather than with real-world data. He presented no explanation for this procedure - not even stating whether real-world data existed or not. Because of his faith in the TOWGEN-LOKSIM package, Hayward did not seem to consider the lack of any comparison of his results with real-world data to be a serious flaw in his study.

When Lave and De Salvo [56] used a queueing theory model to find the expected walting time per tow at a lock, their input and comparison data consisted of the waiting times experienced by a single towboat during 35 transits of each lock under consideration. They recognized that depending upon data from a single towboat had a number of drawbacks.

The final input required for the queueing model is the service rate at each lock. As argued above, the service rate observed by this towboat probably constitutes a biased estimate of average service rate. The most recent study on the service rate of these locks was for the two years 1949 and 1950.

Lave and De Salvo caution the reader that these figures were almost two decades old at the time and so might not prove reliable. In $1978,22 /$ Wilson [82] reassessed the models developed by Lave and De Salvo and by Hayward. In his paper, he said

\footnotetext{
22 /Note that W1lson's paper appeared 4 years after the Performance Monitoring System had been begun.
} 
The scarcity of delay data prevented De Salvo and Lave from making comparisons over a broader range of circumstances. Although empirical data are not available, results of computer simulations of locks have been published.

Lock and dam studies can be divided roughly into two categories - those which deal with the general problem of (unspecified) traffic passing through an (unspecified) lock(s) and those which are concerned with the operation of a single specific lock. The extensive literature dealing with the replacement of Lock and Dam No. 26 is a prime example of the latter. For those studies centered on a specific lock, data are much more easily obtained. For more general research projects, it is necessary to determine the variation in a given category of data among the locks of the types of waterways under consideration. If this variation is large, then either

- the category can be treated as a parameter and varied according to need, or

- the study must be restricted to a class of locks for which the variation in the parameter is small.

However, in either case, the appropriate data must be available for input, calibration and comparison with output. Moreover, the data from various locks must be comparable - that is, the same things must be measured and, in as much the same way as is possible. As an example, the entry time 23 for a tow might be defined (and measured) to begin when

- the water level in the chamber has reached the proper level (so that the recycling time has ended), or when

23 /Even greater difficulty is encountered when trying to measure the entry time of a tow which, approaching a lock and finding no queue, can enter the lock directly from the reach without making a stop beforehand. 
- the lock gates have been opened sufficiently so that a tow can enter the chamber, or when

- the lockmaster gives the tow captain permission to begin his approach to the lock, or when

- the waiting tow actually starts its approach to the lock. Similarly, chamber time, exit time, delay time, etc. for a tow can be defined in several different ways.

In 1974 the Corps of Engineers introduced the Performance Monitoring System (PMS), a program under which a wide variety of data would be collected by lock personnel for each lockage, vessel and shift. The PMS was intended to measure the service provided to the navigation industry on the inland waterways. The Peat, Marwick, Mitchell Company prepared a data collection nanual [67] for use at all locks on the waterways of the United States. This manual contained the forms and procedures to be followed by lock personnel to record and prepare the data inputs for PMS. These data were used by the Corps of Engineers to prepare extensive statistical information about the state and operations on American waterways and to provide both input and comparison data for analyses of traffic congestion, waiting times in a queue, lock capacity, etc. It is evident, however, from reading the available domestic literature on waterway traffic, that in the years since the PMS program was begun, researchers have not made adequate use of the PMS data that are accessible to them.

One important advantage of using a single highly detailed collection manual throughout the entire inland waterways system was that researchers could expect data obtained from different portions of the system to be measuring the same thing in the same way. Thus, these data could be meaningfully compared 
and even co-mingled. As pointed out above, commonly used terms had not always been defined in the same way by different authors in the past. The PMS program should lead to less ambiguity and more conformity in the literature. 


\section{Error Sensitivity}

The sensitivity of a model can be defined as the relative size of the fluctuation in the output of the model compared to the size of the variations in the input which cause the fluctuation. Such variations or deviations can be the result of

- errors in the input data,

- errors induced by simplifying assumptions concerning the workings of real-world system,

- errors induced by mathematical approximations.

The sensitivity of a model with respect to any of these errors is a measure of the confidence one can reasonably have in the output of the model. The sensitivity of a model can be determined either by a mathematical analysis or by purposely introducing fluctuations in the input, assumptions, procedures, etc. and then observing the resulting change in the output.

Many authors have pointed out that for large values of the traffic intensity, the average delay time and the average length of a queue at a lock are very sensitive to the average arrival rate. (For example, see Page 63 of this report.) The average delay time and the average length of a queue at a lock are also sensitive to the probability distribution of the tow arrivals (Poisson arrivals vs regular arrivals) but the level of sensitivity to the probability distribution of the tow arrivals is much below the level of sensitivity to the arrival rate.

As part of the PTTSC simulation program of 1971, Gimbel [39] studied the sensitivity of the version of LOKSIM existing at that time to a number of simplifying assi uptions that had been incoporated into the model. He examined these 
assumptions and the effect of replacing them by premises more closely reflecting the actual operations of a waterway. These included

- the introduction of separate locking time distributions for up-stream and down-stream traffic,

- a reevaluation of Howe's [48] formula for the speed attainable by a tow in a channel,

- improving the method for determining the type of lockage required by a given towboat and barge flotilla,

- an examination of tow delays based on channel width, the no-passing rules, and other channel restrictions.

Gimbel described the level of sensitivity of the model to each of these changes in the model. For example, he concluded that the delays due to channel restrictions are small in comparison with lockage delays and need not be included in the model for short reaches. Unfortunately, Gimbel did not provide specific numerical values documenting the size of changes in the output data resulting from each of these changes in the model.

As part of Rao's study [69] in 1977, he predicted the year in which traffic levels through Lock and Dam No. 26 would reach the capacity of the lock. This prediction was made for the existing two chamber lock configuration and for two possible lock replacements then under consideration. The basis for these predictions was the expected annual throughput tonnage. Rao performed a sensitivity analysis of the annual throughput to lock and vessel characteristics. Unlike the sensitivity analysis of Gimbel described above, the one performed by Rao was mathematical in nature. Rao had derived a formula for the throughput tonnage in terms of the service rate at the lock, the number of barges of various types being used by shippers, and the average loading per barge. In order to find the sensitivity he differentiated the throughput tonnage with 
respect to each of these variables. This ylelded the expected rate of change which would occur in the tonnage when each of the variables was changed. A mathematical approach to sensitivity such as Rao's is a rarity in the literature on traffic on a waterway.

In 1979, Rochberg [72] made an extensive study of the advantages and disadvantages of queueing theory and computer simulation as methods for estimating the capacity and average delay time at a lock. As part of this study he examined the sensitivity of each method to the data and assumptions on which it depends. He also pointed out a number of flaws inherent in each method. For example, it is a standard procedure in queueing theory to use the average value for a variable, rather than the individual values that the variable takes on. Thus, if we have two rectangles, one 3 high by 5 wide and the other $5 \mathrm{high}$ by 7 wide then the average area of the two rectangles is 25 (one half of 15 plus 35). On the other hand, if the average area of the rectangles is computed as the product of the average height (4) and the average width (6) then we obtain an average area of 24 , an error of $4 \%$. The same error occurs when the total tonnage per tow is obtained as the product of the average number of barges per tow and the average tonnage per barge.

Rochberg expressed the opinion that, in general, computer simulations provide a more satisfactory method for modeling the operations of a waterway than does queueing theory. However, queueing theory can be used to enhance the effectiveness of a computer simulation. For example, it is universally agreed that computer simulation runs should be "long" - though the specific advantage of long runs is seldom stipulated. Using queueing theory it is possible to answer questions such as: How long nust a computer simulation run be in order to determine (within a specified degree of certainty) whether the queue at a lock 
will tend to grow indefinitely or will fluctuate about some finite queue length?

There are several important reasons for performing a sensitivity analysis on a model:

- to determine what level of quality is required for the input data,

- to determine whether some portions of the model must be modeled in finer detail than others,

- to determine what confidence can be placed in the output of the model,

- to determine what length a computer simulation should be and to determine how many runs should be made before changing the values of the parameters.

A sensitivity study usually requires a more difficult and more subtle analysis than did the construction of the model itself. In addition, there is not the sense of immediacy about a sensitivity analysis as there is for the analysis of the real-world situation. Unfortunately, it is very tempting to devote all of one's energy to the model and ignore the sensitivity completely. 


\section{Other Modes of Transportation}

In order to recognize and appreciate the complexities involved in commercial traffic on a waterway, it is helpful to compare traffic on a waterway with traffic using other modes of transporation. There is a fundamental similarity between traffic on a waterway and traffic using any other mode of transportation. The basic scenario describing commercial traffic traveling on a locked waterway is:

- there is a single traffic-way which, for the most part, is used simultaneously by two streams of traffic traveling in opposite directions and not interfering with each other,

- there are a number of bottlenecks in the traffic-way at which

- traffic is slowed considerably,

- the two streams of traffic interfere with each other,

- traffic may be permitted in only one direction at a time.

There are several other transportation situations which also fit this general description to a greater or lesser extent:

- aircraft arriving and departing at an airport, perhaps using the same or nearby runways,

- a single-lane bridge on a two-lane country road,

- a railroad spur as part of a railroad system,

- a drawbridge over a navigable waterway,

- an intersection of two highways or city streets,

- a two-lane road in which a portion of one lane is closed (as for repairs).

Undoubtedly there are other transportation phenomena which approximate this basic scenario. 
The similarity between scenarios describing locks on a waterway and bottlenecks encountered when using other modes of transportation suggests that research performed in the context of these other modes of transportation might be applicable to operations on a waterway. On the other hand, it is highly unlikely that a computer simulation of any other mode of transportation would contribute substantially to a computer simulation of a waterway. The current state-of-the-art in computer simulation of waterborne traffic (e.g., the INSA program) is the culmination of a decade of research and has reached a level of sophistication, flexibility and accuracy not of ten found in research devoted to other means of transportation. On the contrary, it is much more likely that analyses of other modes of transportation by means of computer simulation could profit by borrowing from the research performed on waterway traffic. It appears safe to conclude that if research performed in the context of some other mode of transportation is to make a contribution to the analysis of a waterway, then it would necessarily be in the area of mathematical queueing theory.

One drawback of queueing theory as a tool for modeling is its inflexibility. Even a relatively minor change in the operation being modeled may result in a serious complication in the formulation of the queueing model or in its mathematical tractibility. Thus, incorporating features found in the operation of a waterway into a queueing model developed in the context of another mode of transportation may be a difficult problem. There are several aspects of tow traffic through a lock for which counterparts at the bottlenecks in other modes of transportation seldom, if ever, exist. Among these rather unique aspects of tow traffic are

- the lateral maneuverability of a tow on a wide river,

- the distinction between a long entry and a short entry, 
- multiple and setover lockages,

- the use of a helper boat,

- the inability of the bottleneck, when empty, to accept traffic from either direction without substantial preparation,

- the exceptionally long time that a tow actually spends in the 1 ock $^{24} /$. It is thus clear that to apply to the lock and dam situation research based on another mode of transportation will generally require extensive, and possibly prohibitive, adjustments in order to make it relevant. In addition, for many bottleneck problems, the walting time is inconsequential (e.g., at a singlelane bridge on a lightly traveled country road) and has not merited the intensive research effort which has been made for traffic through a lock. There appears to be no form of transportation in which the length of delay times at a bottleneck reaches those which are common at a busy lock. Nevertheless, a number of papers have been written concerning the flow of traffic through a bottleneck on other modes of transportation.

The Science Citation Index and the On-Line Bibliographic Retrieval System were used to search the literature to locate those papers which treat the problem of two streams of traffic passing through a bottleneck where only a single stream can pass at a time, but which were not concerned specifically with waterway traffic. In 1977, Eshcoli and Adiri [36] considered a single-lane bridge on a two lane road. Their aim was to obtain the steady-state distribution and the expectation of the flow time as a function of the bridge's length, or equivalently, of the time spent crossing the bridge. They defined the flow time as the interval between the arrival of a car at the

\footnotetext{
${ }^{24}$ /In other modes of transportation, the time acutally spent in the botter $=k$, rather than in a queue leading to the bottleneck, is so short as to be insignificant.
} 
bridge and the departure of the car at the other end. This differs from the service time (which they did not consider) since, in their model, they assumed that several cars traveling in the same direction can be crossing the bridge at the same time. They further assumed that traffic would continue to flow in one direction unitl no waiting cars in that direction remained to be serviced. Traffic would then immediately begin flowing in the other direction. Also, they assumed that cars traveling in the same direction maintain the same (constant) speed and a fixed safety distance from each other. No comparison was made between results obtained theoretically and either real-world or simulated data.

A related model using vehicle-acutuated traffic lights controling the intersection of two roadways was discussed by Darroch, Newell and Morris [26] in 1964. In this model, once the light at the intersection has turned green in either direction, it remains green until there occurs a time period of a pre-assigned length during which there is no queue in that direction. At that point the light turns red in that direction and green in the opposite direction. Otherwise this scenario is very similar to the one studied by Eshcoli and Adiri. The literature dealing with bottleneck problems, either in the abstract or in terms of some other mode of transportation, appears to be very limited. The two papers discussed above are representative of the current state-of-the-art in modeling traffic bottlenecks, not in the context of waterway traffic, as exemplified in the published literature. Although these studies were performed in terms of automobile traffic, the general approach and the mathematical tools used are very similar to those commonly employed in studying tows passing through a lock. However, the scenario of tows passing through a lock seems to have received much more attention than other bottleneck problems. Non-waterway research would appear to have very 
Iittle to contribute to the treatment of the corresponding waterway problem in the areas of simulation construction and the application of queueing theory. Nevertheless, there are several papers in the transportation research literature (written in a context other than traffic on a waterway) which presented ideas that might be carried over profitably to studies of waterway traffic. For example, in 1979, Newell [63] presented a survey and critique of the literature dealing with airport delay and airport capacity. In this paper, Newell made no attempt to actually calculate either capacity or delay. Instead, he developed careful descriptions of the operations which take place at either a single runway airport or at one with several parallel runways. In terms of these operations, he formulated precise definitions of airport capacity, delay time, arrival rate, service rate, etc. for arriving and departing aircraft serving a mix of several different types of planes. Finally, he pointed out several possible areas for research $(\mathrm{e} . \mathrm{g} \cdot$, the effect of FAA safety regulations on airport capacity and delay times the possible use of incentives to smooth out periods of peak demand, the desirability of sequencing planes in takeoffs and landings, etc.).

In 1978, Carson [17] considered techniques for reducing the variance of variables involved in a computer simulation of a queueing process. Reducing the variance of a variable results in a decrease in the length of computer runs needed to attain a desired level of confidence in the output. In a subsequent paper in 1980, Carson and Law [18] showed that there were several different orders in which a computer simulation of a $G / G / s$ queueing system can estimate the variables being sought (delay time, queue length, arrival rate, etc.). It was then shown that the best results are obtained when those variables with the smallest variances are estimated first and the remaining variables are estimated in terms of these. 
In 1978, Rosenbloom [73] 1isted 22 major classes of promising techniques for reducing congestion in highway traffic and analyzed each of them singly and in a number of combinations. In some cases, implementing several techniques simultaneously results in an improvement in traffic flow greater than the sum of the improvements accrueing from the individual techniques. Such reinforcement does not always occur. Occasionally, different techniques for improving traffic flow cancel each other out when they are used simultaneously. Unfortunately, many of the techniques considered are relevant for highway traffic, but not for a waterway (e.g., the use of telephone calls in place of automobile trips). Nevertheless, the procedure is novel and might be carried over to waterway research.

In 1980, Nihan and Holmesland [64] explored the possibility of using a recently developed mathematical technique called "time series analysis" to forecast short term traffic volume. Monthly data on the volume of traffic using a particular freeway segment were collected for the period 1968-1976. Using these data, a forecast was made of the volume of traffic for 1977. This forecast turned out to be very accurate. The scheme described by Nihan and Holmesland is simple to describe, flexible and easy to use. It might prove to be an improvement over methods currently used in navigational research to forecast tonnage levels of various commodities. 


\section{Conclusions and Recommendations}

A great deal of effort has been expended by a large number of researchers ir. modeling the flow of tow traffic through a portion of an inland waterway. This effort can be divided into two distinct categories according to the main tool used in the construction of the model, namely: computer simulations or mathematical queueing theory. Both computer simulations and queueing theory models have been studied in great detail in the last 15 years. Substantial progress has been made in that period in identifying many of the areas within each model which did not adequately reflect the operation of the waterway. In many cases it has been possible to make modifications in the model which resulted in greater accuracy in the output.

It is generally agreed that computer simulations of any kind have definite drawbacks and 1imitations $25 /$ However, within these recognized bounds, the large scale simulations which have been directed to the operation of an extended inland waterway have been quite successful so that results now obtained (e.g., from the INSA program) enjoy a great measure of acceptance within the research community. With the avallability of large quantities of data from the PMS, it became possible to determine the accuracy of computer packages for different portions of the inland waterways system. Thus, any cases in which the computer simulation models still do not adequately describe the real-world operations may be identified and, hopefully, corrected. Undoubtedly refinements of one sort or another in computer simulation techniques will continue to be made in the future, but the extensive testing to which models currently avallable have already been subjected suggests that there is only a limited amount of room remaining for major improvements. 
The same sanguine picture cannot be presented for the current state-of-the-art with regard to the application of mathematical queueing theory to even a single lock, much less to an extended waterways system. In the current mathematical literature devoted to tow traffic through a lock, there is still signif1cant disagreement concerning the proper probability distributions and queue discipline parameters to be used in order to provide an accurate model. This is particularly true for

- a lock with two (possibly unequal) chambers,

o a lock which is not isolated from other locks and whose input is therefore influenced by the outputs of adjacent locks. However, even in the simplest case (that 1s, an isolated lock with one chamber), the complicated scenario describing the passage of a tow through a lock has presented difficulties which queueing theory has not completely overcome. A large portion of the queueing theory research now in the literature centers around a specific $10 \mathrm{ck}$, and has been made to accomodate the peculiarities found there. Such research has enjoyed a certain degree of success in producing output data about as accurate as that produced by computer simulation. However, the attempts to use queueing theory to describe a "general" lock (so that the results would be universally applicable) have not been successful, and the current state-of-the-art leaves much to be desired.

It is generally agreed that when a queuelng theory model of an operation is available which is as accurate as the state-of-the-art simulation of that operation, then the advantages of queueing theory outweigh those of simulation. Unfortunately, such a queueing theory model for an operation as complex as passing a tow through a lock usually does not exist. In a standard text on operations research, Hillier and Lieberman [46] have written: 
Although considerable progress has been made in developing analytical queueing results, there still remain many potentially useful queueing models which are extremely difficult or impossible to analyze mathematically. It appears that simulation... offers the best hope of eventually obtaining usable results for such models. Simulation has already been used many times to analyze unique queueing-type problems as they have arisen in practice.

Choosing between queueing theory research and research devoted to computer simulation is not an easy task. The likelihood that a queueing theory study will produce a usable model is significantly smaller than the likelihood that a computer simulation would produce usable results but when a usable queueing theory model is produced, it has numerous advantages over a simulation model. Selecting either alternative over the other is a calculated risk. Certainly, the ideal would be to have both kinds of research. If a choice is unavoidable, the nod would seem to go to computer simulation. Perhaps even better than choosing one or the other would be to follow Rochberg's [72] suggestion of combining computer simulation with queueing theory $26 /$.

It is understandable that editors of scientific journals must limit the space available to a single research report. In these reports, authors emphasize the results they have obtained and downplay (or completely ignore) the methods used, the data required, the sensitivity studies performed, the number and lengths of their computer runs, etc $27 /$. It is important that authors (especlally those supported by the Corps of Engineers) prepare not only a paper suitable for publication in a technical journal but also a longer, more detalled report to appear in mimeographed form only for the use of serious scholars. This report should contain all of the important details of the work that could not be included in the published version. Even when such a report is prepared the problem remains of publicizing its existence and getting it into the hands of research workers. 
Finally, in order that these unpublished reports meet the needs of future researchers, a set of documentation standards should be prepared by the Corps of Engineers for use by its own research personnel and by researchers it supports (and, hopefully, by other workers in the area, as well).

There is a very large mathematical literature dealing with the theory of queues in an abstract manner, that is, not in the context of any particular application. As a part of this survey, a substantial portion of that literature was examined with the hope of finding specific research which might be applicable to the problem of tow traffic on an inland waterway. In reading the recent queueing theory ifterature it soon became clear that the problems inherent in modeling waterway traffic are quite different from those studied in the large majority of mathematical papers. For example, the assumption of independence in arrivals, service times, etc. is extremely common in the literature because without it, the problem becomes intractable. However, this assumption is seldom valid in the real-world, and certainly not at a lock. Also, the mathematical Iiterature deals with parameters that are fixed over long periods of time. At a lock, parameters change according to the time of day, the weather conditions, the lock crew, the tow crew, even according to the amount of debris in the water. In the majority of the mathematical Iiterature, given queueing systems are studied to obtain their properties. Researchers dealing with traffic through a lock (especially a multiple chamber lock) are still in disagreement as to which (if any) of the classical queueing systems are appropriate. Finally, the mathematical literature deals with many subjects that are not relevant to a lock (e.g. queues in network $28 /$,

\footnotetext{
$28 /$ In a network the customer has the choice among several routes between his origin and destination.
} 
infinitely many servers, balking $29 /$, etc.). The papers on modeling the traffic at a lock by means of queueing theory that we have examined in Section 8 of this report have recognized the difficulties that have just been described. The queueing theory used in these papers (especially [40] and [72]) is at the state-of-the-art level. Basically, the obstacle is not with the mathematics of queueing theory, but with the deviations of the operations at a lock from the common assumptions of the theory. Nevertheless, mathematical queueing theory still has a contribution to make, primarily as an adjunct to computer simulation. However, it is reasonable to expect that as additional queueing theory research is performed in the future, addressing the difficulties described above, new models will be devised which capture more accurately the features of waterway traffic. Such research should be supported, but with the understanding that the problems are extremely difficult and are likely to be solved only after long, painstaking work.

Mathematics is not a static science. New and powerful mathematical tools are regularly developed and added to the literature. Several of these hold promise for contributing to our ability to model waterway traffic. For example, time series analysis [7] has been used successfully in predicting trends in a wide range of applications. Markov renewal and semi-Markov processes are two other recently developed tools dealing with probabilistic situations which reflect many of the traits of the operations at a lock. Whether or not any of these disciplines can contribute to either our understanding of the operations at a lock or to our ability to construct better models remains to be seen.

\footnotetext{
29 /Balking refers to the option of the customer to leave the queue without service.
} 


\section{REFERENCES}

1. A. T. Kearney \& Co., Improvement Program for the Panama Canal - 1969 , Chicago, 1969.

2. American Waterways Operators, Inc., Inland Waterborne Commerce Statistics, 1976 .

3. Anonymous, Instruction for Navigation Lock Design Standard 303-65, Moscow, $19661-13$.

4. Armstrong, R., Replacement - Lock and Dam No. 26. Plan Considered. J Waterways and Harbors Division, ASCE, Feb. 1970 (96) 49-63.

5. Avi-Itzhak, B., Maxwe11, W. L. \& Miller, L. W., Queueing wth Alternating Priorities, Operations Research 1965 (13) 306-318.

6. Bottoms, E. E., Practical Tonnage Capacity of Canalized Waterways, J Waterways and Harbors Division, ASCE, Feb. 1966 (92) 33-46.

7. Box, G\& Jenkins, G., Time Series Analysis Forecasting \& Control, Holden-Day, San Fransciso, 1976.

8. Bronzini, M. S., TOWGEN: A Tow Generation Model for Inland Waterway Simulation, Waterways Systems Simulation Vol. III. TTSC 7110 , Pennsylvania Transportation and Traffic Safety Center, University Park, PA 1971 .

9. Carrol1, J. L., Waterway Lock Simulation Model. Papers - Sixth Annual Meeting, Transportation Research Forum, 1965, 217-238.

10. Carroll, J. L., Capacity of a Waterway Lock via Simulation. Occasional Paper No. 6, Center for Research, College of Business Administration, Pennsylvania State University, University Park, 1968.

11. Carroll, J. L. \& Bronzini, M. S., Simulation of Waterway Transport Systems, Transportation Engineering J. TE 3, ASCE, 1971, 527-539.

12. Carrol1, J. L. \& Bronzini, M. S., Summery Report, Waterway Systems Simulation Vol. I, TTSC 7108, Pennsylvania Transportation and Traffic Safety Center, University Park, PA 1971.

13. Carrol1, J. L. and Bronzini, M. S., Waterway Transportation Simulation Models: Development and Application, Water Resources Research, 1973 (9) 51-63.

14. Carroll, J. L., Bronzini, M. S. \& Hayward, J. C., Analysis of Waterways Systems: Summery Report. Waterways Systems Simulation Vol. VI, TTSC 7112. Pennsylvania Transportation and Traffic Safety Center, University Park, PA 1972 .

15. Círroll, J. L., Rao S. \& Wilson, H. G., Great Lakes - St. Lawrence Seaway S nulation Studies, Summery Report, Vol. III, TTSC 7318, Pennsylvania Transportation and Traffic Safety Center, University Park, PA 1973. 
16. Carroll, J.L., Rao, S. \& Wilson, H. G., Alternative Methods for Increasing the Efficiency of the Inland Waterways, 1974 Spring Meeting Papers, the Society of Naval Architects and Marine Engineers, 1974, 3.1-3.17.

17. Carson, J., Variance Reduction Techniques for Simulated Queueing Processes, Technical Report No. 78-8, Department of Industrial Engineering, University of Wisconsin, Madison, WI 1978.

18. Carson, J. \& Law A., Conservative Equations and Variance Reduction in Queueing Simulations. Operations Research 1980 (28) 535-548.

19. Case, L. And Lave, L. B., To11s: Efficiency and Equity; Issues for Inland Waterways, Management Science 1977 (23) 811-819.

20. Clark, W., Hochstein, A. \& Kistler, R., (CACI Inc.) Waterway and Rail Capacity Analysis, 1976. Unpublished.

21. Courtsal, D. P., The Marine Business in the Central United States. Transactions of the Society of Naval Architects and Marine Engineers, 1971 (79) 542-572.

22. Daggett, L. L., Ankeny, T. D. \& E1land, J. A., A New Generalized Waterway Simulator: WATSIM IV. U.S. Army Engineers Waterways Experiment Station, Vicksburg, MS 1977.

23. Daggett, L. L. \& McCarley, R. W., Capacity Studies of Winfield Locks, Kanawha River, West Virginia. Miscellaneous Paper H-77-1 United States Army Engineering District, Huntington, West Virginia, 1977.

24. Daggett, L. L. \& Shows, L., Untitled, 24th International Navigation Congress, Leningrad, 1977, 227-250.

25. Daggett, L. L., McCarley, R. W. \& Stinehour, J., Use of Tow Sequencing Procedures to Increase the Capacity of Existing Lock Facilities, Miscellaneous Paper H-74-5, United States Army Waterways Experiment Station, Vicksburg, MS 1974.

26. Darroch, J., Newell, G. F. and Morris, R., Queues for Vehicle-Actuated Traffic Lights, Operations Research, 1964 (12).

27. Davis, J. P., Problems of Inland Waterway Lock Dimensions. J Waterways and Harbors Division, ASCE May, 1970, WW2 (96) 451-466.

28. Deazeley, R. \& Wilson, J., Ship Lock Simulation Facility, Dock and Harbor Authority. 1972 (53) 96-97.

29. Decker, E., Replacement - Lock and Dam No. 26: History, Objectives and Scope. J Waterways and Harbors Division, ASCE, Feb. 1970 (96) NW1, 1-7.

30. Desai, K., A Study of Tow Arrival Processes at Inland Waterway Locks. Technical Note No. 76. Pennsylvania Transportation and Traffic Safety Center, University Park, PA 1972. 
31. De Salvo, J. S. \& Lave, L. B., An Analysis of Towboat Delays. J Transport Economics and Policy, 1968 (2) 232-241.

32. Doig, A., A Bibliograph on the Theory of Queues, Biometrika 1957 (44) 490-514.

33. Dunan J. \& Coutheillas G., Etude de la Capacite Economique d'un Groupe d'Ecluses, Transports, 1970 (149) 46-53.

34. Eickhorst, A. G. \& Koch, D., Replacement - Lock and Dam No. 26: Lock Capacity, Procedure and Scope, J Waterways and Harbors Division, ASCE, WW1, 1970 (96) 15-25.

35. Erlang, A., Solution of Some Problems in the Theory of Probabilities of Significance in Automatic Telephone Exchanges, Post Office Electrical Engineer's J 1917-1918 (10) 189-197.

36. Esccoli, Z \& Adiri, I., Single-Lane Bridge Serving Two Lane Traffic. Naval Research Logistics Quarterly 1977 (24) 113-125.

37. Gaum, C., Selection of Parameters and Determination of Method for Assessing the Transport Capacity of the Ohio River Waterway, Permanent Assoctation of Navigation Congresses. Bulletin, 1970 (1).

38. Gelencser, G., Improving the Effective Capactiy of a Navigation System. 24th International Navigation Congress, Leningrad, 1977, 1-21.

39. Gimbel, C. H., WATSIM: A Waterway Trnasport Simulator, Waterways System Simulation, Vol. II, TTSC 7109, Pennsylvania Transportation and Traffic Safety Center, University Park, PA 1971.

40. Glassey, C. P. \& Ross, S. M., Queueing Models for Multiple Chamber Locks, Transportation Science, 1976 (10) 391-403.

41. Harrison, J., An Analytical Model to Predict Ship Transit Capacities of Sea-Level Canals. Miscellaneous Paper H-69-10, United States Army Waterways Experiment Station, Vicksburg, MS 1969.

42. Hayward, J. C., LOKSIM: A Multiple Chamber Lock Simulation Model, Waterways Systems Simulation, Vol. IV, TTSC 7111, Pennsylvania Transportation and Traffic Safety Center, University Park, PA 1971.

43. Hayward J. C., Simulation Analysis of a Multiple Chamber Lock on an Inland Waterway, TTSC 7211, Pennsylvania Transportation and Traffic Safety Center, Pennsylvania State University, University Park, PA 1972.

44. Hayward, J. C., The Inapplicability of the Classic Queueing Model to the Waterway Lock Situation. Unpublished, 1972.

45. Herendeen, J \& Staadeker, P., Application of System Simulation Models: Ohio River Navigation Study. TTSC 7113. Pennsylvania Transportation and Traffic Safety Center, University Park, PA 1971. 
46. Hillier, F. S. \& Lieberman, G. J., Introduction to Operations Research Holden-Day, San Francisco, 1968.

47. Hoffmeister, J. F. \& de Neufville, R., Optimizing the Supply of Inland Waterway Transport. ASCE J Transportation Engineering 1973 (99).

48. Howe, C. W., Mathematical Models of Barge Tow Performance, J Waterways and Harbors Division, ASCE WW4 1967 (93) 153-166.

49. Kleinrock, L., Queueing Systems, John Wiley and Sons, Inc. New York, 1975.

50. Koch, D., Replacement - Lock and Dam No. 26: Projecting Waterborne Commerce - Inland Navigation. J Waterways and Harbors Division ASCE, WW 1 $(1970),(96) 9-14$.

51. Koehler, R., Schriftenreihe des Instituts fur Verkehrswesen des Universitat Karlsruher, Verkehrsablauf auf Binnerwasserstrassen, 1968 (3) $1-89$.

52. Koehler, R., Das Problem des Anschluss-verkehrn vor Schubeinheiten, die auf Kanalen verkehren an die Streckenschubboote auf dem Rhein. Zeitschrift fur Binnenschiffahrt und Wasserstrassen $\mathrm{Nr} 1 / 701970,12-14$.

53. Kooman, I \& De Druijn, P., Lock Capacity and Traffic Resistence of Locks, G.P.O The Hague (1975) 1-98.

54. Koopman, B., Air-Terminal Queues under Time-Dependent Conditions, Operations Research, 1976, 1089-1113.

55. Kray, C., Design of Ship Channels and Maneuvering Areas, J Waterways, Harbors and Coastal Engineering Division, ASCE, WW1, $1973^{-}(\overline{99) 89-110}$.

56. Lave, L. B. \& De Salvo, J. S., Congestion, Tolls and the Economic Capacity of a Waterway, J Political Economy, 1968 (76) 375-391.

57. Lenz, K. H., Die Warteschlangentheorie und Ihre Anwendung auf den Verkehr an Schulsen. Undated.

58. Leutzbach, W. \& Lenz, H.-H., Wartenzeiten an Schlusen, Transportation Research, 1967 (1) 359-365.

59. Luce, A. M. \& Sandor, P., A Systems Approach to the Problem of Increasing the Effective Capacity of the Welland Canal, Proceedings, Transportation Research Forum, Chicago, IL 1965.

60. Matlin, G. Gokhshteyn, G\& Kunakhovich, G., Integrated Deep Water System of Inland Waterways in the European Territory of the U.S.SR., Izdatel'stvo, Transport, Moscow 1971 (Translated by the Office of the Chief of Engineers, Department of the Army).

61. Matuszewsk1, J., (Dynamics Research Corp.) A Feasibility Study of Rea1Time Performance Monitoring Systems for the Inland Waterway, 1974.

Unpublished. 
62. National Waterways Study, Institute for Water Resources, United States Army Corps of Engineers, Ft. Belvoir, VA 1977-1980.

63. Newe11, G. F., Airport Capacity and Delay, Transportation Science, 1979 (13) 201-241.

64. Nihan, N. \& Holmesland, K., The Use of the Box and Jenkins Time Series Techniques in Traffic Forecasting, Transportation, 1980 (9), 125-143.

65. Nishida, S., Watanabe, $\mathrm{N} \&$ Eguchi, H., Analysis of Shipping Traffic Capacity of Narrow Waterways on the Urage Channe1, 22nd International Navigation Congress, Paris, 1969 77-96.

66. O'Brien, G\& Crane, R., The Scheduling of a Barge Line. Operations Research 1959 (7) 561-570.

67. Peat, Marwick, Mitchel1 \& Co., Data Collection Manual for the Performance Monitoring System, 1974. Unpublished

68. Pritsker, A. and Young, R., Simulation with GASP - PL/I, John Wiley \& Sons, 1975, New York.

69. Rao, S., Optimizing Navigation Investments to Relieve Lock Congestion on Waterways, PTI 7706, Pennsylvania Transportation Institute, Pennsylvania State University, University Park, PA 1977.

70. Rea, J. C. \& Nowading, D.C., Simulation of Multiple Channel Deep Draft Navigation Systems, Waterway Systems Simulation, Vol. V. TTSC 7112, Pennsylvania Transportation and Traffic Safety Center, University Park, PA 1971.

71. Riordan, J., Stochastic Service Systems, John Wiley and Sons, New York, 1962.

72. Rochberg, R., Analysis of Capacity of Locks, 1979, 1-88. Unpublished.

73. Rosenbloom, S., Peak-Period Traffic Congestion: A state-of-the-art Analysis and Evaluation of Effective Solutions, Transportation, 1978 (7), $167-191$.

74. Rousselin, M., (Untitled) 22nd International Navigation Congress, Paris, 1969, Permanent International Association of Navigation Congresses, $35-52$.

75. Schofield, R., Speed of Ships in Restricted Navigation Channels, J Waterships, Harbors and Coastal Engineering Division, ASCE, 1974, (100) 133-150.

76. Schultz, R. P., Graphic Analysis of Waterway Capactiy, J Waterways and Harbors Division, ASCE, WW4, 1967 (93) 177-184. 
77. Summers, L. I., Lamarche, L. \& Ku, K., Computer Simulation of Seaway Traffic, Analytical Gateways to Transport Expansion, Proceedings, 6th National Forum on Systems in Transportation, Ohio Chapter, Transportation Research Forum, 1969, 99-105.

78. Takacs, L., Introduction to the Theory of Queues, Oxford University Press, New york, 1962 .

79. United States Army Corps of Engineers, Locks and Dam No. 26, Formulation Evaluation Report, St. Louis District, 1975.

80. United States Army Corps of Engineers, Inland Navigation Systems Analysis (INSA) 5 volumes, Unpublished, 1976.

81. Waugh, R., Economics of Channels and Maneuvering Areas, J Waterways, Harbors and Coastal Engineering Division, ASCE, WW4, $197 \overline{1} \frac{\mathrm{J}}{(97) 671-686 .}$

82. Wilson, H. G., On the Applicability of Queueing Theory to Lock Capacity Analysis, Transportation Research, 1978 (12) 175-180. 
NBS.114A (REV. 2.8C)

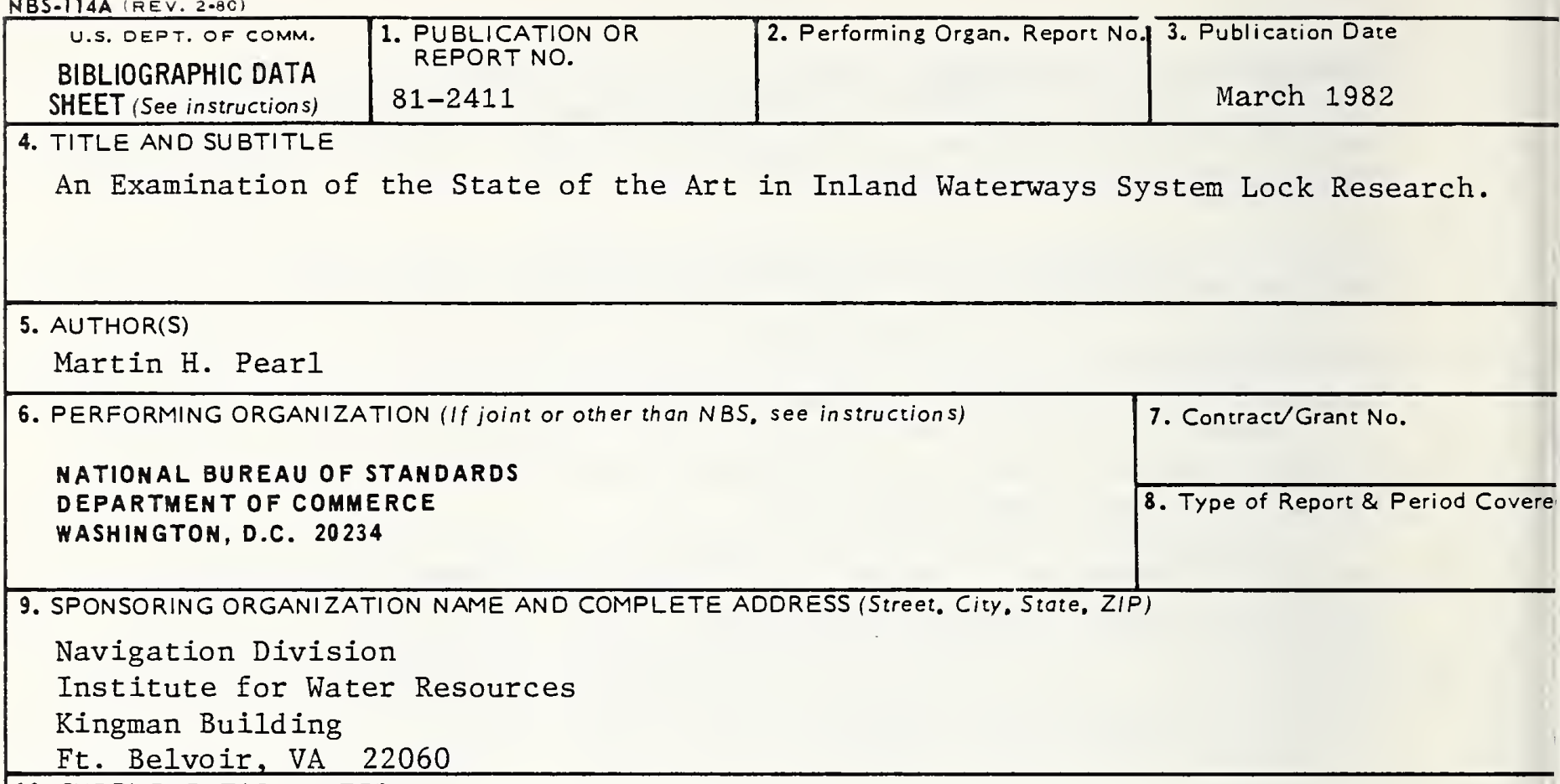

10. SUPPLEMENTARY NOTES

Document describes a computer program; SF-185, FIPS Software Summary, is attached.

11. ABSTRACT (A 200-word or less factual summary of most significant information. If document includes a significant bibliography or literature survey, mention it here)

Locks which pass waterborne traffic through dams act as bottlenecks and interfere with the free flow of traffic. Two complementary mathematical tools have been used to determine the maximum capacity of a lock and the operating procedures which achieve this capacity. These are i) computer simulations of traffic flows, and, ii) the mathematical theory of queues. A large-scale, multi-purpose simulatior package was developed at the Pennsylvania State University and expanded by the Army Corps of Engineers. Several researchers have attempted to model the operation at a lock using mathematical queueing theory. In addition, queueing theory has been applied to analyze traffic flow through a bottleneck on other modes of transportation. Also, queueing theory has been used to study problems which arise in the use of computer simulations.

12. KEY WORDS (Six to twelve entries; alphabetical order; capitalize only proper names; and separate key words by semicolons) capacity; dam; lock; queue; simulation; waiting time

13. AVAILABILITY

Unlimited

For Official Distribution. Do Not Release to NTIS

Order From Superintendent of Documents, U.S. Government Printing Office, Washington, D.C. 20402 .

X Order From National Technical Information Service (NTIS), Springfield, VA. 2216I
14. NO. OF PRINTED PAGES

111

15. Price

$\$ 12.0$ 

